\title{
Molecular sized Eu-oxide clusters in defining optical properties in crystalline $\mathrm{ZnO}$ nanosponges
}

\author{
Soham Mukherjee, ${ }^{1,}{ }^{*}$ Sarmad Naim Katea, ${ }^{2}$ Emille M. Rodrigues,${ }^{3}$ Carlo. U. Segre, ${ }^{4}$ Eva Hemmer, ${ }^{3}$ Peter Broqvist,${ }^{2}$ \\ Håkan Rensmo, 1,* Gunnar Westin ${ }^{2, *}$ \\ ${ }^{1}$ Department of Physics and Astronomy, Angström laboratory, Uppsala University, 75236 Uppsala, Sweden \\ ${ }^{2}$ Department of Chemistry-Angström, Angström Laboratory, Uppsala University, 75121 Uppsala, Sweden \\ ${ }^{3}$ Department of Chemistry and Biomolecular Sciences, University of Ottawa, 10 Marie Curie, Ottawa, Ontario, K1N 6N5, \\ Canada \\ ${ }^{4}$ Center for Synchrotron Radiation Research and Instrumentation and Department of Physics, Illinois Institute of Technology, \\ Chicago, Illinois 60616, USA
}


ABSTRACT: The detailed structure of $\mathrm{ZnO}$ doped with 5 at.\% (metal) of the large aliovalent $\mathrm{Eu}^{3+}$-ions was investigated using EXAFS to describe the local $\mathrm{Eu}$ and $\mathrm{Zn}$ coordination. The microstructure, crystalline phases, contents and $\mathrm{ZnO}$ unit-cell parameters for the $\mathrm{ZnO}: 5 \% \mathrm{Eu}$ sponges synthesised at 200 to $900{ }^{\circ} \mathrm{C}$ were obtained by XRD, SEM, and TEM analysis. XRD showed peaks solely of $\mathrm{h}-\mathrm{ZnO}$ for the $600{ }^{\circ} \mathrm{C}$ sample, while heating at $700{ }^{\circ} \mathrm{C}$ and higher caused phase separation into h$\mathrm{ZnO}: \mathrm{Eu}$ and $\mathrm{c}-\mathrm{Eu}_{2} \mathrm{O}_{3}$. XRD showed a close to zero increase in $\mathrm{ZnO}$ unit cell-volume of ca. 0.4 vol\%, compared to un-doped $\mathrm{ZnO}$ for the non-phase separated, clean oxide made at $600^{\circ} \mathrm{C}$. The $\mathrm{Zn}$ EXAFS data showed an almost intact local $\mathrm{ZnO}$ structure. The Eu EXAFS showed an unusually low coordination number $(\mathrm{CN})$ of ca. 5 for the 200-600 ${ }^{\circ} \mathrm{C}$ samples, while the $\mathrm{CN}$ increased for higher temperatures, in concert with the formation of c- $\mathrm{Eu}_{2} \mathrm{O}_{3}$. 23 DFT-generated theoretical $\mathrm{ZnO}$ structures containing Eu-clusters built from 1 to $4 \mathrm{Eu}^{3+}-\mathrm{Zn}^{2+}$-vacancy- $\mathrm{Eu}^{3+}$ pairs were compared with the experimental data. The lowest formation energies and $\mathrm{ZnO}$ unit-cell volume increase versus un-doped $\mathrm{ZnO}$ (0.6-0.7 vol\%), were obtained when combining two or four $\mathrm{Eu}^{3+}-\mathrm{Zn}^{2+}$-vacancy- $\mathrm{Eu}^{3+}$ pairs into $\mathrm{Eu} 4$ and $\mathrm{Eu} 8$ clusters showing an average $\mathrm{Eu} \mathrm{CN}$ of ca. 5. These theoretically determined lowest energy structures were all in good agreement with the experimental results obtained by EXAFS and XRD. Photoluminescence excitation and emission spectra performed on the $\mathrm{ZnO}: 5 \mathrm{at} \% \mathrm{Eu}$ sponges obtained at various temperatures, showed strong quenching of the characteristic $\mathrm{Eu}^{3+}$ transitions for samples obtained at 600 and $800{ }^{\circ} \mathrm{C}$, most likely due to changes in the $\mathrm{ZnO}$ defect states, which are crucial for $\mathrm{Eu}^{3+}$ excitation, and due to self-quenching upon Eu clustering and c$\mathrm{Eu}_{2} \mathrm{O}_{3}$ phase separation. Thus, the optical data further supported Eu clustering found by EXAFS, DFT and XRD techniques, corroborating structure-property relationships in these materials. Overall, as far as we can find, the findings reported herein point to a doping structure very different from those previously proposed in the literature. It demonstrates that the semiconductor $\mathrm{ZnO}$ can host molecular-sized clusters of metal-oxides, very dissimilar to $\mathrm{ZnO}$.

\section{Introduction}

$\mathrm{ZnO}$ based semiconductors have gained enormous interest due to their potential as solar cells,(1-10) photo-catalysts,(11-14) diluted magnetic semiconductors,(15-17) piezoelectric nano-generators,(1,3) sensors,(1-3,18-22) opto-electronics, $(1,2,18)$ green fuel catalysts,(23-27) and energy storage.(4,28-30) Doping with various metal ions has been extensively investigated to optimise the electronic structure or to endow $\mathrm{ZnO}$ with additional optical, magnetic or catalytic properties. However, in spite of an immense research effort over the last two decades there is a large variety of results reported on the properties of doped $\mathrm{ZnO}$, some of them being even contradictory. This may to a great degree be related to the crystal quality, grain boundaries and perhaps most importantly, the doping structure (31-34), i.e. the spatial distribution and local coordination of the dopant-ions in the host lattice. In spite of this, there are few studies that describe the dopant structure in sufficient detail to connect properties with structure. To further complication, the structure and chemical contents vary with synthesis technique and heattreatment, and have a profound effect on the optical and magnetic properties, as well as the electronic band-structure. A recent example is the study of $\mathrm{ZnO}$ :Co aiming for diluted magnetic semi-conductors (DMS), which showed promise for spin-polarised electron transport with potential to revolutionise the electronics industry. $(15,16,35)$ In this area, the large number of reports give a scattered picture of the magnetic properties, and sometimes completely contradictory results. When investigating with atomistic probes, it was shown that the differences depended on the cobalt oxidation state, local formation of spinel $(\mathrm{Zn}, \mathrm{Co})_{3} \mathrm{O}_{4}$ and clustering of $\mathrm{Co}^{2+}$-ions residing at $\mathrm{Zn}^{2+}$ positions, yielding a paramagnetic 
response from peripheral cobalt-ions.(36-43) This is a general finding applicable also to other oxide semiconductors, that strongly hampers the progress of e.g. solar hydrogen catalysts, as can be exemplified by the Ti-doped $\alpha-\mathrm{Fe}_{2} \mathrm{O}_{3}$, showing very different properties depending on synthesis techniques; from improving the photo-catalytic activity to reducing it.(44)

Lanthanide ( $\mathrm{Ln}$ )-doped semi-conductors, including $\mathrm{ZnO}$ have gained interest as potential photocatalysts or optoelectronic devices,(45-47) where the most studied system is Eu-doped ZnO. Some of the investigated materials contain unexpected high doping levels of up to $5 \% \mathrm{Eu}$ and higher, when considering the much larger ionic radius and aliovalency of $\mathrm{Eu}^{3+}$ compared to the $\mathrm{Zn}^{2+}$-ions of the host lattice. Therefore, there has been an ongoing discussion on the reality and nature of such Eu-doped $\mathrm{ZnO}$, not the least due the close to zero changes in XRD unit cell-dimensions observed with high levels of $\mathrm{Eu}^{3+}$ doping. A short review focused on the synthesis and connected properties is given in the in ref. (48) besides general reviews on Ln-doped $\mathrm{ZnO}$ and their properties and more comprehensive reviews are found in $(45,47)$.

It has recently been proven beyond doubt, that the $\mathrm{Eu}^{3+}$ ions are situated within the $\mathrm{ZnO}$ nanocrystals when using synthesis temperatures from 200 to $700{ }^{\circ} \mathrm{C} .(48,49)$ In these studies, TG analysis, XRD, XPS, IR spectroscopy, SEM, TEM-ED/EDS, STEM-EELS mapping, and optical measurements were used to describe the chemistry and structure of $\mathrm{Eu}$ doped $\mathrm{ZnO}$. It was found that at 200 to $500{ }^{\circ} \mathrm{C}$, there were also minor amounts of organic residues or carbonate present, besides the $\mathrm{Eu}^{3+}$ ions. This is expected to be a general feature for chemically synthesised $\mathrm{Ln}$ doped $\mathrm{ZnO}$ samples, although, it is typically not investigated. For the $5 \% \mathrm{Eu}$ samples, phase separation took place yielding nano $c-\mathrm{Eu}_{2} \mathrm{O}_{3}$ crystals at the surface of lesser Eu-doped $\mathrm{ZnO}$. Hence, there exists a temperature window of clean, Eu-doped $\mathrm{ZnO}$ between 500 and $700{ }^{\circ} \mathrm{C}$ without any discernible phase separation or impurities. At lower Eu-doping levels of $0.5-1 \%$, this window widened to reach up to $900{ }^{\circ} \mathrm{C}$. It was also found, that in line with the literature, there were very small changes in XRD unit cell-parameters upon doping with the large $\mathrm{Eu}^{3+}$ ions. DFT modelling, using dimeric $\mathrm{Eu}^{3+}$ ion pairs flanking a metal vacancy for charge neutrality placed in the $\mathrm{ZnO}$ structure, did not result in any significant reduction of the unit cellvolume, compared to a linear Vegard type model using the calculated ionic radius of $83.5 \mathrm{pm}$ for four coordinated $\mathrm{Eu}^{3+}$ ions.(48) This indicates that while it might seem possible for the flanking $\mathrm{Eu}^{3+}$ ions to make use of the $\mathrm{Zn}^{2+}$-ion vacancy void between two $\mathrm{Eu}^{3+}$ ions, the surrounding $\mathrm{ZnO}$ lattice would be compressed around the site, resulting in increased $\mathrm{ZnO}$ cell-parameters resulting in a small energy gain compared to larger clusters.

Thus, while it was shown that the $\mathrm{Eu}^{3+}$ ions resided within the $\mathrm{ZnO}$ crystals, without a clearly visible phase separation in TEM imaging or XRD analysis, their local dopant structure remained unknown. Therefore, to be able to understand how the large amounts of the big $\mathrm{Eu}^{3+}$ ions can be introduced into the $\mathrm{ZnO}$ phase, without changing the $\mathrm{ZnO}$ unit cell-volume, a more detailed study on the $5 \%$ Eu-doped $\mathrm{ZnO}$ was conducted using EXAFS. This technique allows to describe the local $\mathrm{Eu}^{3+}-$ 
and $\mathrm{Zn}^{2+}$-ion coordination numbers, bond-lengths, and neighbouring conditions. These data were compared with DFT modelling, using $23 \mathrm{Eu}^{3+}-\mathrm{Zn}^{2+}$ vacancy $-\mathrm{Eu}^{3+}$ (abbreviated as $\mathrm{Eu}^{3+}-\mathrm{Zn}_{-}$vac.-Eu ${ }^{3+}$ hereafter) pair-based clusters of sizes up to $8 \mathrm{Eu}^{3+}$ ions. Their calculated Eu coordination number, Eu$\mathrm{Eu}$ distances, $\mathrm{ZnO}$ unit cell-volume and total energy were compared with the experimentally obtained local structures obtained from EXAFS data and the close-to-zero volume expansion in $\mathrm{ZnO}$ unit cellparameters found by XRD analysis. A very good agreement between the theoretical and experimental data was found for three clusters containing four or eight Eu-ion membered clusters. This allows to understand the unexpected doping structure and how the $\mathrm{ZnO}$ unit cell-dimensions can be retained on doping with high levels of large, alio-valent ions such as $\mathrm{Eu}^{3+}$.

Furthermore, the changes in coordination over the temperature range, 200 to $900{ }^{\circ} \mathrm{C}$, were examined to follow the Eu-dopant coordination; from the lowest synthesis temperature of $200{ }^{\circ} \mathrm{C}$, to the clean, Eu-doped oxide obtained at $600{ }^{\circ} \mathrm{C}$, and further into the temperature range, $700-900{ }^{\circ} \mathrm{C}$, where the $\mathrm{Eu}$ is expelled from the $\mathrm{ZnO}$ to yield $5-10 \mathrm{~nm}$ sized $c-\mathrm{Eu}_{2} \mathrm{O}_{3}$ particles on the $\mathrm{ZnO}$ sponge surface. The Eu-doped $\mathrm{ZnO}$ microstructures were also further described with SEM and TEM imaging, although more thorough microscopy studies, including TEM-EELS mapping has been provided elsewhere. $(48,49)$ The optical studies provided insight into the energy levels and properties of the minor defects in these materials, not accessible by the TEM and EXAFS probes.

Based on the results obtained in this study, highly complex and to-date unforeseen molecularlike dopant structures are proposed that may shed light on various hard to explain magnetic and optical data for this kind of semi-conductor materials. The findings reported herein also point to a general possibility to form clusters of "misfit"-ions within rigid semi-conductor structures for the design of optical, magnetic, catalytic and transport properties, where typically a high dopant level is desired, while the semi-conductor properties are sensitive to disturbances in the semi-conductor lattice.

\section{Experimental section}

2.1. Chemicals and synthesis. All chemicals were used as received. The actual molecular weights of the hydrated salts were determined gravimetrically as $\mathrm{Eu}_{2} \mathrm{O}_{3}$, after heating at $1000{ }^{\circ} \mathrm{C}$ for at least $3 \mathrm{~h}$. Nanosponges of undoped $\mathrm{ZnO}$ and doping with $5 \mathrm{~mol} \% \mathrm{Eu}$ in $\mathrm{ZnO}$, were synthesised as given in detail in reference.[46] Briefly, zinc-dinitrate-hexahydrate $\left(\mathrm{Zn}\left(\mathrm{NO}_{3}\right)_{2} 6 \mathrm{H}_{2} \mathrm{O}\right.$, Sigma-Aldrich $\left.>99 \%\right)$, zinc-diacetate-dihydrate $\left(\mathrm{Zn}(\mathrm{OAc})_{2} 2 \mathrm{H}_{2} \mathrm{O}\right.$, Sigma-Aldrich $\left.>99 \%\right)$ and triethanolamine (TEA, SigmaAldrich p.a) in methanol (Scharlau, 99.5\%) was mixed with an appropriate amount of europiumtrinitrate-pentahydrate (Aldrich $99.9 \%, \mathrm{Eu}\left(\mathrm{NO}_{3}\right)_{3} 5 \mathrm{H}_{2} \mathrm{O}$ and triethanolamine (TEA), in methanol (Scharlau, analytical grade 99.9\%). Subsequently, the solution was evaporated to a transparent or

whitish paste on a Petri-dish and heated for $3 \mathrm{~min}$ in a muffle furnace set to 200, 400,600, 700, 800, or $900{ }^{\circ} \mathrm{C}$. Upon heating to $200{ }^{\circ} \mathrm{C}$ or higher temperatures, very light voluminous $\mathrm{ZnO}$ or $\mathrm{ZnO}$ :Eu sponge powders were formed. 
2.2. Sponge microstructure by XRD, SEM, and TEM. The crystallinity of pure and Eu-doped $\mathrm{ZnO}$, obtained by heating the precursor paste for $3 \mathrm{~min}$ at temperatures between 200 and $900^{\circ} \mathrm{C}$, was studied with powder X-ray diffraction (XRD) analysis using $\mathrm{Cu} K_{\alpha}$ radiation. The phase contents, unit cell-parameters, and crystal sizes were determined with the Topas software. The following cif-files were employed: $\mathrm{ZnO}$ (PDF Card 00-036-1451, hexagonal $\mathrm{ZnO}$, space group $P 6_{3} m c$ ) and $\mathrm{Eu}_{2} \mathrm{O}_{3}(\mathrm{PDF}$ Card 00-034-0392, cubic $\mathrm{Eu}_{2} \mathrm{O}_{3}$, space group $I-a 3$ ). The overall microstructure of the nanosponges was studied with a Zeiss Merlin field emission gun scanning electron microscope (SEM), while the detailed microstructure was studied with a JEOL 2100F transmission electron microscope operated at $200 \mathrm{kV}$ (TEM).

2.3. Local structure by EXAFS. Room temperature Extended X-ray Absorption Fine Structure (EXAFS) measurements were performed at the Materials Research Collaborative Access Team (MRCAT) bending magnet beamline (Sector 10) at Argonne National Laboratory's Advanced Photon Source. The MRCAT bending magnet beamline uses a water-cooled Si (111) double crystal monochromator and collimating slits for energy selection and optimal energy resolution. EXAFS measurements were performed in transmission mode at the $\mathrm{Zn} \mathrm{K}$ and $\mathrm{Eu} \mathrm{L}_{3}$ edges for the $\mathrm{ZnO}: 5 \% \mathrm{Eu}$ nanosponges prepared at $200,600,700,800$, and $900^{\circ} \mathrm{C}$. The amount of sample was adjusted to yield a total absorption coefficient $(\mu \mathrm{x})$ of around 2.5 after the edge in order to ensure a linear response. Measured quantities of powdered sample, amounting to ca. $40 \mathrm{mg}$, were thoroughly mixed with boron nitride and pressed into $10 \mathrm{~mm}$ diameter pellets which were and mounted in Kapton tape for EXAFS measurements. A $\mathrm{Zn}$ foil was measured with each scan as reference to track any energy shift between the scans. The reference energies obtained were used for edge alignment during the data processing. Commercial $\mathrm{Eu}_{2} \mathrm{O}_{3}$ was used as Eu reference material, while the elemental reference was calibrated using an Fe foil. Each scan was taken with a step of $5 \mathrm{eV}$ in the pre-edge region, $0.2 \mathrm{eV}$ in the XANES $(-50 \mathrm{eV}$ to $+50 \mathrm{eV})$ region and $2 \mathrm{eV}$ for the rest of the scan. The number of scans was decided based on the statistics. Typically, for a given sample. EXAFS data were analysed by the IFEFFIT interactive XAFS data analysis package, using AUTOBK for background subtraction and the FEFF6 program for calculating theoretical scattering amplitudes and phases for a pair of atoms, using the input file prepared by ATOMS program that uses the standard crystallographic data. For each measured X-ray absorption spectrum, the EXAFS signal $\chi(k)$ was extracted using AUTOBK. $\chi(k)$ is generally defined as:

$$
\chi(k)=\Sigma_{j} \frac{N_{j} S_{0}^{2} f_{j}(k) e^{2 R_{j} / \lambda(k)} e^{-2 k^{2} \sigma_{j}^{2}}}{k R_{j} 2}\left[\sin 2 k R_{j}+\delta_{j}(k)\right]
$$

where $k$ is the photoelectron wavenumber, $f_{j}(k)$ and $\varphi_{j}(k)$ represent the photoelectron back-scattering amplitude and phase for the $j^{\text {th }}$ shell, $\lambda_{j}(k)$ is the photoelectron inelastic mean free path, $N_{j}, R_{j}$, and $\sigma_{j}^{2}$ represent the coordination number, interatomic distance and mean-square disorder in $R_{j}\left(j^{\text {th }}\right.$ coordination shell), and $S_{0}^{2}$ the amplitude reduction factor. Multiple scans for each edge were properly aligned, merged and normalised, using Athena software. The background below $R_{b k g}=1.0 \AA$ was 
minimised by using the built-in AUTOBK algorithm. The final merged scans for each metal edge were simultaneously analysed, using the theoretical fitting standards computed with FEFF6 software. Input for FEFF was prepared using the ATOMS program and the crystallographic data. The data were analysed using FEFFIT software. The errors were estimated by a standard Levenberg-Marquardt, nonlinear minimization of the statistical $\chi 2$ parameter, built within the FEFF6 program. Fits to all data in $\mathrm{k}$ and R (real part and magnitude) space, extracted EXAFS parameters and their associated error limits are detailed in the Supporting Information.

2.4. Cluster modelling by DFT. The electronic structure calculations performed in this work are based on density functional theory (DFT) in the implementation with plane waves and pseudopotentials. The exchange-correlation energy contribution to the total energy was modelled using the density functional proposed by Perdew-Burke-Ernzerhof (PBE)(50,51) Projector Augmented Wave (PAW) pseudo-potentials[52,53] describing explicitly 4, 12 and 9 electrons were used for $\mathrm{O}\left(2 \mathrm{~s}^{2} \mathrm{p}^{4}\right)$, $\mathrm{Zn}\left(3 \mathrm{~d}^{10} 4 \mathrm{~s}^{2}\right)$ and $\mathrm{Eu}\left(4 \mathrm{f}^{6} 5 \mathrm{~d}^{1} 5 \mathrm{p}^{6} 6 \mathrm{~s}^{2}\right)$, respectively. For $\mathrm{Eu}$, the chosen pseudo-potential has earlier been used to accurately describe the $\mathrm{Eu}^{3+}$ oxidation state. In the current investigation of Eu-dopants in $\mathrm{ZnO}$, explicit effects of spin-polarisation in the $\mathrm{Eu}^{3+}$ ions were not accounted for. All calculations were performed using the Vienna Ab Initio Simulation Package (VASP).[54-57]

The bulk hexagonal $\mathrm{ZnO}(h-\mathrm{ZnO})$ host was modelled using an orthorhombic representation of the hexagonal $\mathrm{ZnO}$ as basis, with a unit cell size of $9.86 \times 10.60 \times 11.38 \AA^{3}$, containing in total $48 \mathrm{ZnO}$ units, as obtained from the cell optimisation at the current level of theory. Upon Eu-doping, the same unit cell was used to construct supercell structures, always ensuring that the doping concentration was kept constant at $4.17 \mathrm{at} \% \mathrm{Eu}$ with respect to the total number of metal ions in the stoichiometric $\mathrm{ZnO}$. The cut-off energy, truncating the plane-wave basis set, was set to $600 \mathrm{eV}$, and the k-point sampling of the Brillouin zone was kept at correspondingly a 3 x 3 x 3 k-point sampling, using the Monkhorst-Pack scheme, for the smallest unit cell. Optimisation of position of the ions and cell volumes were performed for all presented structures until the largest force on each atom was smaller than $0.001 \mathrm{eV} /$ atom. Along with total energy evaluations, radial distribution functions (partial and full) were computed to allow for comparison to the results concerning distances and coordination numbers obtained from the experimental EXAFS data.

2.5. Optical properties. Excitation and emission photoluminescence spectra were obtained using a Horiba QuantaMaster ${ }^{\mathrm{TM}}$ 8075-21 spectrofluorometer, equipped with a double additive excitation monochromator with triple gratings, a single emission monochromator with triple gratings, and a UVVIS PMT detector (Hamamatsu PMT R928). The excitation source used for the recording of steadystate excitation and emission spectra was a $75 \mathrm{~W}$ continuous Xenon lamp, while a $450 \mathrm{~W}$ pulsed Xenon lamp was used for the time-resolved emission spectra. All samples were analysed at room temperature, 
(a)

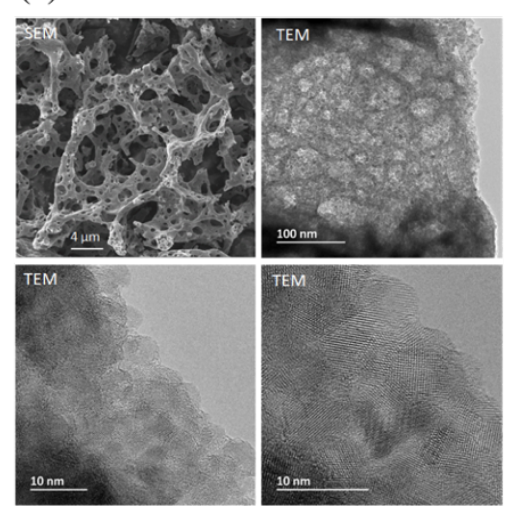

(b)



(c)

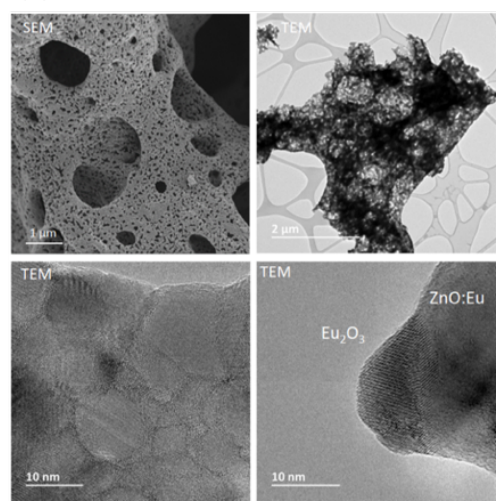

Figure 1. SEM and TEM images of $\mathrm{ZnO}: 5 \% \mathrm{Eu}$ sponges heated for $3 \mathrm{~min}$ at (upper figure) $200{ }^{\circ} \mathrm{C}$, (mid figure) $600{ }^{\circ} \mathrm{C}$, and (lower figure) $800^{\circ} \mathrm{C}$.

in solid-state as pressed pellets between $1 \mathrm{~mm}$ thick quartz windows using a $90^{\circ}$ configuration between the excitation beam and emission collection.

\section{Results and Discussions}

\subsection{Sponge microstructure by XRD, SEM and TEM}

The synthesis of sponge structures, built of nano-crystallites, was previously reported in detail.(48,49,58) In the present study, $\mathrm{ZnO}$ and $\mathrm{ZnO}: 5 \% \mathrm{Eu}$ nanosponges were prepared by heating a precursor paste for $3 \mathrm{~min}$ at 200, 400,600, 700, 800, and $900{ }^{\circ} \mathrm{C}$, in air. SEM and TEM images showing the microstructures of the $\mathrm{ZnO}: 5 \% \mathrm{Eu}$ sponges, obtained after heating at 200,600 , and $800{ }^{\circ} \mathrm{C}$, respectively, are shown in Figure 1.

The $\mathrm{ZnO}: 5 \% \mathrm{Eu}$ nanosponge obtained at $200{ }^{\circ} \mathrm{C}$ contained minor amounts of organic residues, including carboxyl groups, while heating at $400{ }^{\circ} \mathrm{C}$ left only minor amounts of carbonate.(48) Heating at $600{ }^{\circ} \mathrm{C}$, removed all residues to yield a pure, Eu-doped zinc-oxide sponge without detectable phase segregation. $(48,49)$ On heating at $700{ }^{\circ} \mathrm{C}$, the first very minor phase segregation was observed by TEM (Figure 1), while it was hard to detect in the XRD (Figure 2). After heating at $800{ }^{\circ} \mathrm{C}$, the cubic- $\mathrm{Eu}_{2} \mathrm{O}_{3}$ phase was clearly segregated at the $\mathrm{ZnO}$ sponge surface as ca. 5-10 $\mathrm{nm}$ sized particles, as shown by TEM and XRD (Figure 1 and 2). The XRD phase analysis indicated that ca. 50 and $30 \mathrm{wt} \%$ of the Eu remained in the $\mathrm{ZnO}$ at 800 and $900{ }^{\circ} \mathrm{C}$, respectively. The Bragg reflections corresponding to $\mathrm{ZnO}$ and $\mathrm{Eu}_{2} \mathrm{O}_{3}$ are indexed in Figure 2(a), corresponding to reference $\mathrm{ZnO}$ (PDF Card -00-036-1451) and $\mathrm{Eu}_{2} \mathrm{O}_{3}$ (PDF Card - 00-034-0392) data. From the TEM images, it can be observed that the $\mathrm{ZnO}$ grain connectivity was more intimate for the 600 and $800^{\circ} \mathrm{C}$ sponges showing a complete interface between the $\mathrm{ZnO}: \mathrm{Eu}$ grains, compared with that of the $200{ }^{\circ} \mathrm{C}$ sponge, which showed more rounded, less tightly connected grains. 

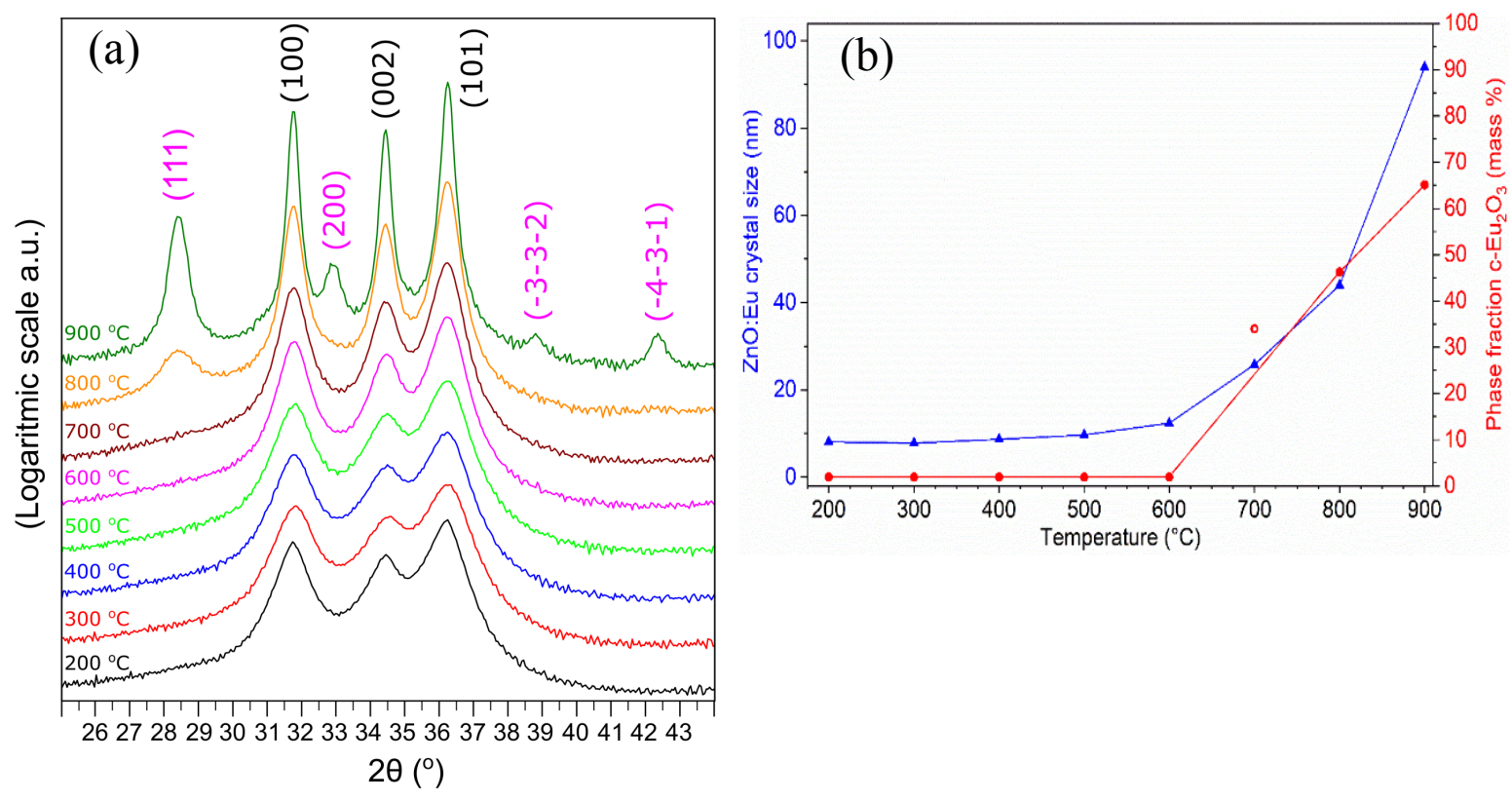

Figure 2. (a) XRD patterns versus temperature graph of $\mathrm{ZnO}: 5 \% \mathrm{Eu}$ sponges heated for $3 \mathrm{~min}$ at 200, 300, $600,700,800$, and $900{ }^{\circ} \mathrm{C}$, showing the emergence of the $c-\mathrm{Eu}_{2} \mathrm{O}_{3}$ phase. (b) A graph of the XRD derived approximate mass fraction of $\mathrm{Eu}_{2} \mathrm{O}_{3}$ in the $\mathrm{ZnO}$ :Eu sponge and $\mathrm{XRD}$ derived $\mathrm{ZnO}$ :Eu crystal size versus temperature.

\subsection{Local structure of the ZnO:5\%Eu sponges by EXAFS}

EXAFS. The element selectivity of the EXAFS technique allows to probe to the local environment of the host and dopant ions separately, which is essential for the understanding of especially the Eu-dopant structure. $\mathrm{ZnO}$ and $\mathrm{ZnO}: 5 \% \mathrm{Eu}$ nanosponges prepared by heating for $3 \mathrm{~min}$ at 200, 400, 600, 700, 800, and $900{ }^{\circ} \mathrm{C}$, respectively, were studied with EXAFS, along with $c-\mathrm{Eu}_{2} \mathrm{O}_{3}$ for comparison.

Zn environment. Figure 3 a shows $\chi(\mathrm{k})$ functions for the $\mathrm{Zn} \mathrm{K}$ edge in the $\mathrm{ZnO}: 5 \% \mathrm{Eu} \mathrm{ZnO}$ nanosponges. The $\chi(\mathrm{k})$ oscillations remained well-defined up to high photoelectron wavenumbers of $\mathrm{k}$ $\sim 14 \AA^{-1}$, which indicates a high degree of short-range order in the $\mathrm{Zn}$ environment. The major frequency components of the $\chi(\mathrm{k})$ functions appeared quite similar to that of pure $\mathrm{ZnO}$, indicating that the presence of $\mathrm{Eu}$ did not modify the local environment around $\mathrm{Zn}$ to any appreciable degree. The $\chi(\mathrm{k})$ amplitudes increased with synthesis temperatures from 200 to $900{ }^{\circ} \mathrm{C}$, which may to some extent be related to the increasing crystallite sizes with increased synthesis temperatures in the range 700 to $900{ }^{\circ} \mathrm{C}$. The main dampening however, was found for the 200 and $600{ }^{\circ} \mathrm{C}$ samples, for which the crystal sizes were fairly small ( $\sim 10 \mathrm{~nm})$, as given by Figure 1. In addition, formation of cavities hosting Eu-oxide clusters within the $\mathrm{ZnO}$ crystals can effectively act as grain boundaries, and thereby reduce the long-range ordering (vide infra). Synthesis temperatures above $600{ }^{\circ} \mathrm{C}$ would reduce the amount of such cavities when $c$ $\mathrm{Eu}_{2} \mathrm{O}_{3}$ is expelled from the $\mathrm{ZnO}$ grains. Thus, the dampening of the $\chi(\mathrm{k})$ amplitudes likely has different origins in the low $\left(<600^{\circ} \mathrm{C}\right)$ and at high $\left(>600^{\circ} \mathrm{C}\right)$ temperature regimes. 

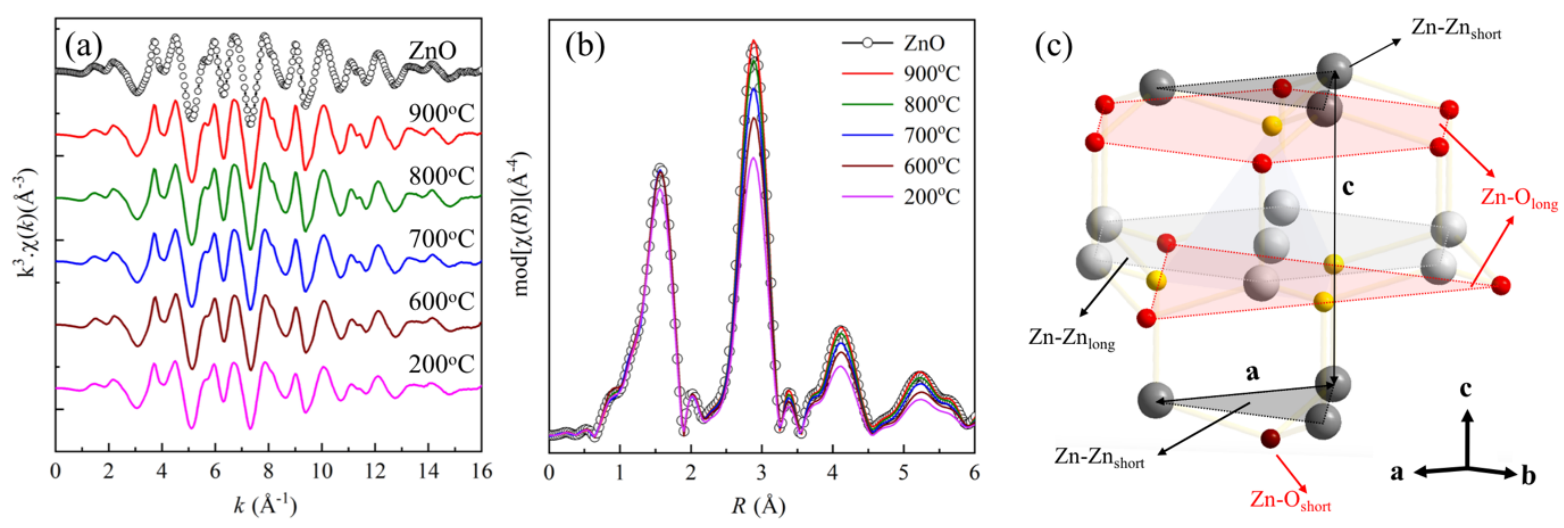

Figure 3. (a) $\mathrm{Zn}-\mathrm{K} \chi(\mathrm{k})$ functions and (b) corresponding Modulus of $\chi(\mathrm{R})$ functions for $\mathrm{ZnO}: 5 \% \mathrm{Eu}$ nanosponges synthesised at 200,600, 700, 800 and $900{ }^{\circ} \mathrm{C}$, and undoped $h$-ZnO for comparison, (c) Spatial distribution of 1NN (4O: yellow), $2 \mathrm{NN}$ (6Zn-Zn $\mathrm{Zn}_{\text {short }}$ dark grey, $6 \mathrm{Zn}-\mathrm{Zn}_{\text {long: }}$ : light grey) and $3 \mathrm{NN}$ (1Zn-O $\mathrm{O}_{\text {short: }}$ dark red, $9 \mathrm{Zn}-\mathrm{O}_{\text {long: }}$ red) atoms ( $\mathrm{NN}$ : near neighbouring).

The dampening effects were more evident in Figure $3 b$, where the individual frequency components of $\chi(\mathrm{k})$ functions were isolated by Fourier transforming $(\mathrm{FT})$ the data to corresponding $\chi(\mathrm{R})$ functions. The peaks observed in the $\bmod [\chi(\mathrm{R})]$ functions correspond to scattering from near neighbouring $(\mathrm{NN})$ atoms occurring at different distances from a central $\mathrm{Zn}$ atom $(\mathrm{R}=0 \AA$ ). Zn EXAFS parameters were extracted by fitting the $\chi(\mathrm{R})$ data over the range 1.1 - $3.5 \AA \AA$ using a Hanning window. Details of the fitting procedures applied and local parameters extracted are provided in the Supporting Information Table S1. An overlay plot of the real part of the $\chi(R)$ functions and their corresponding fits are shown in Figure S1. The 1NN environment revealed three short and one slightly longer Zn-O bonds (Table S1), typical of an asymmetric $\mathrm{Zn}-\mathrm{O}_{4}$ tetrahedral unit in hexagonal $\mathrm{ZnO}$. The $\mathrm{CN}$ slightly below four for the $1 \mathrm{NN}$ for the $200{ }^{\circ} \mathrm{C}$ sample is likely due to surface effects, due to the smaller particle sizes and rounder shape providing less inter- $\mathrm{ZnO}$ grain contacts, exhibiting oxygen-poor faces, and cavities containing Eu-O clusters interrupting the $\mathrm{ZnO}$ crystal, as well as the presence of organic residues.

The second EXAFS peak observed in Figure 3b includes contributions from 2NN (the Zn, Eu coordination shell) and 3NN (the next $\mathrm{O}$ coordination shell). Spatial distributions of 2NN (6 short Zn$\mathrm{Zn}$ and 6 long $\mathrm{Zn}-\mathrm{Zn}$ ) and 3NN (1 short, 6 medium and 3 long $\mathrm{Zn}-\mathrm{O}$ ) interatomic distances are shown in Figure $3 \mathrm{c}$. The coordination numbers of $\mathrm{Zn}\left(n_{\mathrm{Zn}-\mathrm{Zn}}\right), \mathrm{Eu}\left(n_{\mathrm{Zn}-\mathrm{Eu}}\right)$ and $\mathrm{O}$ atoms $\left(n_{\mathrm{Zn}-\mathrm{O}}\right)$ surrounding a $\mathrm{Zn}$ atom extracted from EXAFS analysis are shown Figure 4 a. The sum of $n_{\mathrm{Zn}-\mathrm{Zn}}$ and $n_{\mathrm{Zn}-\mathrm{Eu}}$ gives the total $2 \mathrm{NN}$ coordination number $\left(\mathrm{n}_{2 \mathrm{NN}}\right)$ around $\mathrm{Zn}$. Figure $4 \mathrm{a}$ reveals that starting from a lower $\mathrm{CN}\left(n_{2 \mathrm{NN}}\right.$ of ca. 10), the $\mathrm{n}_{2 \mathrm{NN}}$ increased with increasing annealing temperature approaching the ideal bulk limit value of 12 (pure $\mathrm{ZnO}$ ). Lower $n_{2 \mathrm{NN}}$ values cannot be explained by competing $\mathrm{Zn}-\mathrm{Zn}$ and $\mathrm{Zn}-\mathrm{Eu}$ interactions alone, but are most likely due to a size effect, and hence more prominently observed for higher NN than 1NN (O-shell). Since Zn EXAFS provides volume-averaged local information about all Zn atoms, 
smaller average crystallite sizes occurring at lower temperatures would be reflected locally in the lowering of $n_{2 \mathrm{NN}}$ and $n_{3 \mathrm{NN}}$ values.

The $n_{\mathrm{Zn}-\mathrm{Eu}}$ values are close to the low nominal value of 0.05 , which prompted us to also model the $\mathrm{Zn}-\mathrm{K}$ EXAFS data without any contribution from Eu. A comparative error analysis (Table S2) indeed revealed the models to be rather similar. This test confirmed that Eu-doping did not significantly alter the hexagonal $\mathrm{ZnO}$ lattice locally, but only reduced the short-range order at lower temperatures; an effect connected to cavities occupied by Eu-oxide clusters. This also explains why larger uncertainties were observed when estimating the coordination numbers and interatomic distances for the $\mathrm{Zn}-\mathrm{Eu}$ pairs (Figure 4), where the largest uncertainties were observable for the $900{ }^{\circ} \mathrm{C}$ nanosponges in which the $\mathrm{Zn}$ environment contains a smaller amount of Eu.

The $\mathrm{Zn}-\mathrm{Zn}, \mathrm{Zn}-\mathrm{Eu}$ and $\mathrm{Zn}-\mathrm{O}$ interatomic distances are plotted in Figure 4b. The average Zn-Eu interatomic distances were ca. $0.2 \AA$ longer than the $\mathrm{Zn}-\mathrm{Zn}$ distances, as expected considering that the $\mathrm{Eu}^{3+}$ ions have estimated ionic radii of 84,89 , and $95 \mathrm{pm}$ for $\mathrm{CN}=4,5$, and 6, respectively,(46) compared to $60 \mathrm{pm}$ for tetrahedral Zn-ions.(59) Interestingly, while the synthesis temperature hardly affected the $\mathrm{Zn}-\mathrm{Zn}$ and short $\mathrm{Zn}-\mathrm{O}$ distances of the host $\mathrm{ZnO}$, the $\mathrm{Zn}-\mathrm{Eu}$ and long $\mathrm{Zn}-\mathrm{O}$ (3NN) distances decreased with increasing temperature, more evidently over the $700^{\circ} \mathrm{C}$ to $900^{\circ} \mathrm{C}$ range. It is in this temperature range that the zinc coordination around the $\mathrm{Zn}$ atoms increased to resemble that of pure bulk $\mathrm{ZnO}$, with almost constant $\mathrm{Zn}$-Eu coordination numbers (Figure 4a). These observations are in concert with the XRD and TEM data, revealing expulsion of Eu from the $\mathrm{ZnO}$ :Eu grains forming $c$ $\mathrm{Eu}_{2} \mathrm{O}_{3}$ particles on the surface (Figure 1b,c). These changes were accompanied by a very small decrease in $\mathrm{ZnO}$ unit cell-volume, yielding a material with only 30-50 wt\% of the Eu-oxide residing within the $\mathrm{ZnO}$ grains at 800 to $900{ }^{\circ} \mathrm{C}$ (Figure 1 and 2). The mobility of the metal-ions in this temperature range was also displayed by a fast $\mathrm{ZnO}$ grain-growth, from ca. $10 \mathrm{~nm}$ at $200-600{ }^{\circ} \mathrm{C}$ to $94 \mathrm{~nm}$ at $900{ }^{\circ} \mathrm{C}$, as shown in Figure $2 b$.

These observations indicate that the $\mathrm{Eu}^{3+}$ ions cluster within the $\mathrm{ZnO}$, while not affecting the general $\mathrm{ZnO}$ lattice to any large degree, and that $\mathrm{ZnO}$ :Eu suffers phase separation into lower Eu content $\mathrm{ZnO}: \mathrm{Eu}$ and $c-\mathrm{Eu}_{2} \mathrm{O}_{3}$ at elevated temperatures.

Eu environment. The local environment around the $\mathrm{Eu}$ dopant ions provides experimental insight into the cluster-structure within the $\mathrm{ZnO}$ crystals, which cannot be obtained by the other techniques used. An overlay plot of the $\chi(k)$ functions for Eu-doped $\mathrm{ZnO}$ prepared at different synthesis temperatures as well as $c$ - $\mathrm{Eu}_{2} \mathrm{O}_{3}$, for comparison are presented in Figure 5a. The Eu- $\mathrm{L}_{3}$ EXAFS for the nanosponges prepared at $900^{\circ} \mathrm{C}$ appears similar to that of $c-\mathrm{Eu}_{2} \mathrm{O}_{3}$ with well-defined $\chi(k)$ oscillations extending up to $k \sim 11.0 \AA^{-1}$. The $\chi(k)$ function based on the experimental data becomes slightly less well-defined for the $800{ }^{\circ} \mathrm{C}$ sponge and even more so for lower temperatures resulting in a $k_{\max }$ of ca. $8.5 \AA^{-1}$. This, thus suggests a higher disorder in the Eu local environment for these samples, compared to their $\mathrm{Zn} \chi(k)$ counterpart. 

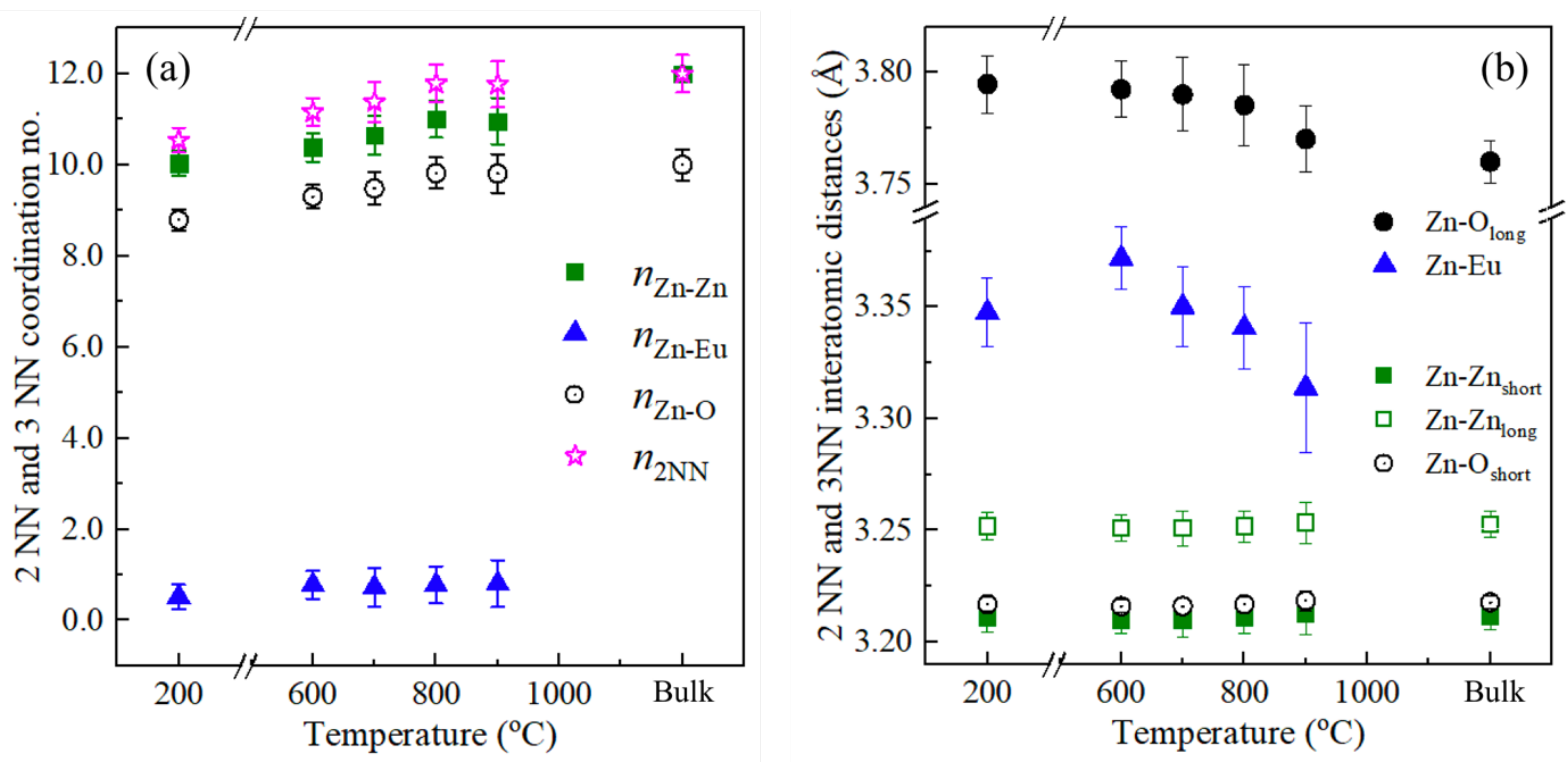

Figure 4. (a) Coordination number of $\mathrm{Zn}, \mathrm{Eu}, 2 \mathrm{NN}(\mathrm{Zn}+\mathrm{Eu})$ and $3 \mathrm{NN}(\mathrm{O})$ about a $\mathrm{Zn}$ atom; (b) Interatomic distances between $\mathrm{Zn}-\mathrm{Zn}$ short (red open circles), Zn-Zn long (red closed circles), Zn-Eu (blue triangles), $\mathrm{Zn}-\mathrm{O}$ short (black open squares), Zn-O long (black closed squares).

The differences in Eu- $\mathrm{L}_{3} \chi(k)$ functions were clearly manifested in the FT of these three compounds, as shown in Figure 5b. It is immediately noticeable that the $1 \mathrm{NN}$ peaks for $\operatorname{Eu} \chi(R)$ appear at longer $R$-values compared to the $1 \mathrm{NN}$ peaks for $\mathrm{Zn} \chi(R)$, as expected from the smaller ionic radius of the $\mathrm{Zn}^{2+}$-ion compared to the $\mathrm{Eu}^{3+}$ ion. The $1 \mathrm{NN}$ peaks for $\mathrm{Eu} \chi(R)$ appeared relatively broad and showed stronger intensity variations, suggesting that the Eu atoms assumed very varied Eu-O coordination environments. The higher NN features, contributed by Eu and Zn, were dampened when comparing the $900{ }^{\circ} \mathrm{C}$ sample with the $800^{\circ} \mathrm{C}$ sample, and became rather diffuse in the temperature regime 200-700 ${ }^{\circ} \mathrm{C}$. This is interpreted as due to surface effects, interference between Eu-Eu and Eu-Zn, and local inhomogeneities. Increased ordering of the Eu local structures with increased synthesis temperature from $700{ }^{\circ} \mathrm{C}$ to $900{ }^{\circ} \mathrm{C}$ is in consonance with the formation of all six coordinated $\mathrm{Eu}$ in the $c-\mathrm{Eu}_{2} \mathrm{O}_{3}$, concluded from XRD and TEM data.

Local structural information about Eu was obtained by fitting the EXAFS data over the range $1.1-4.2 \AA$. An overlay of the real part of the $\chi(R)$ functions and their corresponding fits are presented in Figure 5c. Several possibilities of $\mathrm{ZnO}$-Eu host guest interactions were considered for comparison with doping models used in the literature; metal-site substitution, interstitial doping, local clustering, and phase segregation. The Supporting Information contains further details of the EXAFS analyses and local parameters extracted from these fits (Table S2). The description of $1 \mathrm{NN}$ required two different Eu$\mathrm{O}$ bonds, as given in Table S2. Using a single Eu-O path increased the $\sigma^{2}$ values, indicating that these contributions needed to be accounted for separately. The peak broadening observed in Figure $5 \mathrm{~b}$ is therefore due to an intrinsically larger spatial distribution of Eu-O distances in the 1NN environment. 

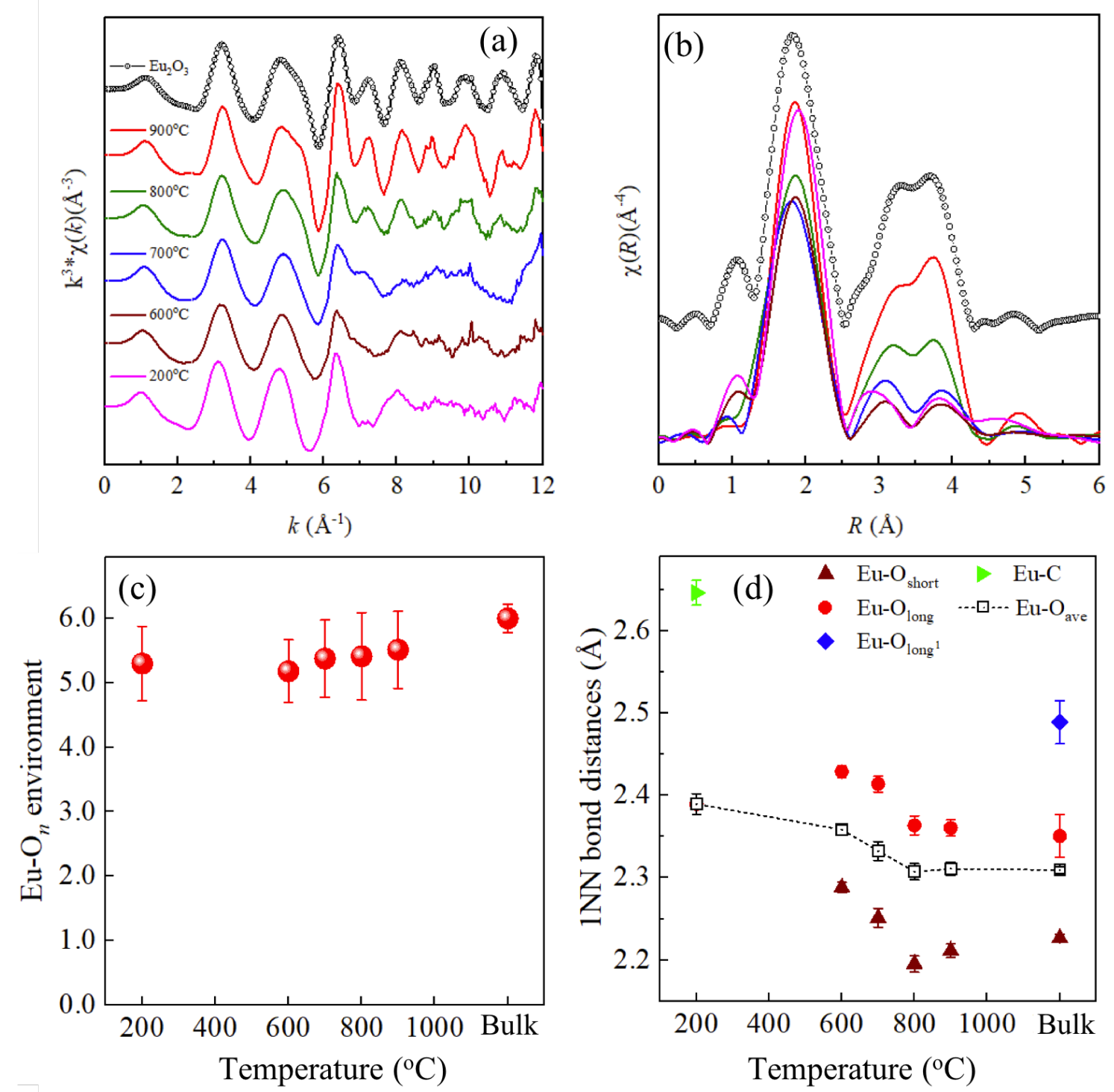

Figure 5. (a) Eu-L3 $\chi(k)$ functions and (b) corresponding modulus of $\chi(R)$ functions the for Eu-doped $\mathrm{ZnO}$ nanosponges synthesised at $900{ }^{\circ} \mathrm{C}$ (red), $800{ }^{\circ} \mathrm{C}$ (olive), $700{ }^{\circ} \mathrm{C}$ (blue), $600^{\circ} \mathrm{C}$ (wine) and $200{ }^{\circ} \mathrm{C}$ (magenta), respectively compared to bulk $c-\mathrm{Eu}_{2} \mathrm{O}_{3}$ (black circles). (c) Evolution of number of $\mathrm{O}$ atoms bonded to $\mathrm{Eu}$ in Eu-doped $\mathrm{ZnO}$ nanosponges synthesised at different annealing temperatures. (d) Eu-O bond distribution in Eu doped $\mathrm{ZnO}$ nanosponges synthesised at different temperatures. Corresponding average Eu-O bond distances for each annealing temperature are represented by the black open squares.

The extra intensity in the $1 \mathrm{NN}$ peak at ca. $2 \AA$ for the $200{ }^{\circ} \mathrm{C}$ sample (Figure 5b), could not be accounted for by interstitial $\mathrm{Zn}$ or Eu doping. Instead, it could stem from organic residues, such as carboxylate groups, not fully removed at $200{ }^{\circ} \mathrm{C}$, as described in earlier studies using TG, XPS and IR spectroscopy.(46)

The description of the $1 \mathrm{NN}$ environment $\left(\mathrm{Eu}-\mathrm{O}_{n}\right)$ around $\mathrm{Eu}$ are given in Figure $5 \mathrm{c}$, d, in terms of average coordination number of $\mathrm{O}$ bonded to $\mathrm{Eu}$ and $\mathrm{Eu}-\mathrm{O}$ bond distances. $\mathrm{Eu}^{3+}$ ions typically attain 
coordination numbers of 6-8.(59) For pure $\mathrm{Eu}_{2} \mathrm{O}_{3}, \mathrm{CN} 6$ is expected for $c-\mathrm{Eu}_{2} \mathrm{O}_{3}$. Figure 6 a shows that the 200 and $600{ }^{\circ} \mathrm{C}$ sponges assumed $\mathrm{CN}$ close to 5 , which is very unusual for any $\mathrm{Ln}^{3+}$-ion. Heating at temperatures of $700{ }^{\circ} \mathrm{C}$ and higher increased $\mathrm{CN}$ towards six for the $900{ }^{\circ} \mathrm{C}$ sample. This is in line with the formation of $c-\mathrm{Eu}_{2} \mathrm{O}_{3}$ having $\mathrm{CN}$ 6, as shown by XRD and TEM. The CN lower than six, found in the $900{ }^{\circ} \mathrm{C}$ sample, is reasonable knowing that ca. $30 \%$ of the Eu was still present in the $\mathrm{ZnO}$ grains and that the $c-\mathrm{Eu}_{2} \mathrm{O}_{3}$ forms small nanoparticles with a large surface area, where the $\mathrm{Eu}$ at the surface may have a $\mathrm{CN}$ lower than six.

Figure $5 \mathrm{~d}$ shows $1 \mathrm{NN}$ distances for all nanosponges. The $200{ }^{\circ} \mathrm{C}$ sample showed an average Eu-O bond length of $2.39 \pm 0.01 \AA$, while the $600{ }^{\circ} \mathrm{C}$ sample showed a slightly shorter average bond length of $2.36 \AA \pm 0.01$, which could be due to some organic groups being coordinated to the $\mathrm{Eu}^{3+}$ ion in the former case. From $700{ }^{\circ} \mathrm{C}$ and up, a decrease in average Eu-O bond-length was observed, eventually attaining close to the ideal Eu-O distances for pure $c-\mathrm{Eu}_{2} \mathrm{O}_{3}$ for $800^{\circ} \mathrm{C}$ and $900^{\circ} \mathrm{C}$. Average Eu-O distances, therefore are significantly longer $(\sim 0.4 \AA)$ than $\mathrm{Zn}-\mathrm{O}$ bond distances $(\sim 1.96 \AA)$. This observation, along with a $\mathrm{CN}$ over 5 completely rule out the possibility of Eu acting as a pure substitutional (60-63) impurity $(\mathrm{CN}=4)$ at $\mathrm{Zn}$ sites in the $h$ - $\mathrm{ZnO}$, regardless of synthesis temperature. The O-shell description from EXAFS neither fits the possible configurations of interstitial doping: tetrahedral voids occurring at $(0,0,3 / 8),(0,0,5 / 8),(2 / 3,1 / 3,1 / 8)$ and $(2 / 3,1 / 3,7 / 8)$, and (b) octahedral voids: $(1 / 3,2 / 3,1 / 4)$ and $(1 / 3,2 / 3,3 / 4)$ nor typically higher coordination numbers of $\mathrm{Eu}(59)$, as elaborated in the Supporting information. Thus, from Figures $5 \mathrm{c}$ and $5 \mathrm{~d}$, it is evident that Eu adopts a bigger, more disordered coordination environment and such mode of doping does not fit any of the generally proposed models for Ln doping in $\mathrm{ZnO}$.

Estimation of absolute coordination numbers of $\mathrm{Zn}\left(n_{\mathrm{Eu}-\mathrm{Zn}}\right)$ and $\mathrm{Eu}\left(n_{\mathrm{Eu}-\mathrm{Eu}}\right)$ surrounding an $\mathrm{Eu}$ atom from higher NN peaks is non-trivial. This arises from the difficulty in decoupling the effects of surface and disorder from the strongly damped $\chi(R)$. Instead, an estimate of the relative fraction of $\mathrm{Zn}$ $\left(f_{\mathrm{Eu}-\mathrm{Zn}}\right)$ and $\mathrm{Eu}$ atoms $\left(f_{\mathrm{Eu}-\mathrm{Eu}}\right)$ surrounding an Eu atom is provided in Figure 6a. The reference for Eu considered here is $c-\mathrm{Eu}_{2} \mathrm{O}_{3}$, so the model of the Eu environment was achieved with a 1:1 distribution of short and long Eu-Eu correlations and one Eu-Zn correlation, as already obtained from fitting the $\mathrm{Zn}$ EXAFS data. If $\mathrm{Eu}^{3+}$ ions were doped homogeneously throughout the $\mathrm{ZnO}$ lattice, the ideal value for $f_{\mathrm{Eu}-\mathrm{Eu}}$ would be 0.05 , considering the nominal doping percentage of $5 \%$ Eu. Figure 6 a clearly shows $f_{\mathrm{Eu}}$ Eu values to be significantly higher than 0.05 , indicating clustering of $\mathrm{Eu}$ in the $\mathrm{ZnO}$ matrix. A closer inspection reveals that for the $200-700{ }^{\circ} \mathrm{C}$ samples the $f_{\mathrm{Eu}-\mathrm{Zn}}: f_{\mathrm{Eu}-\mathrm{Eu}}$ ratio stays close to $1: 1$, but for the 700-900 ${ }^{\circ} \mathrm{C}$ samples the $f_{\text {Eu-Zn }}: f_{\text {Eu-Eu }}$ ratio steeply increases to reach ca. 0.75 for the $900{ }^{\circ} \mathrm{C}$ sample. This is in concert with the ca. $70 \mathrm{wt} \% c-\mathrm{Eu}_{2} \mathrm{O}_{3}$, obtained by XRD. The ca. 1:1 ratio of Eu-Eu and Eu-Zn pairs found for the $200-700{ }^{\circ} \mathrm{C}$ samples indicate that the clusters have to be small to minimise the number of Eu-O-Eu bonds. Since the amount of Eu in the sponges was constant over temperature, an increase in 

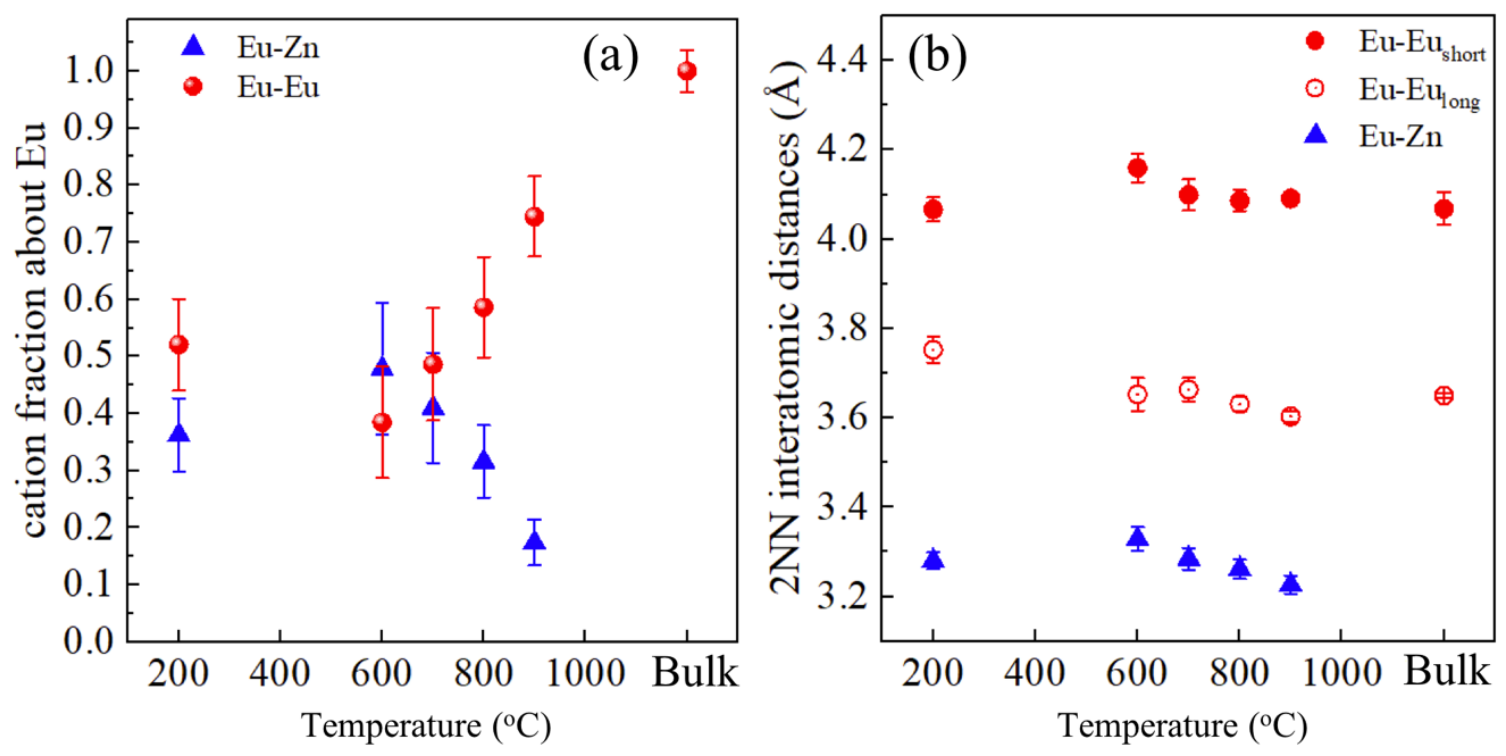

Figure 6. (a) Fraction of $\mathrm{Zn}$ and $\mathrm{Eu}$ bonded to Eu, showing the Eu clustering to increase with temperature. (c) Interatomic $\mathrm{Eu}-\mathrm{Eu}_{\text {short }}, \mathrm{Eu}-\mathrm{Eu}_{\mathrm{long}}$, and $\mathrm{Eu}-\mathrm{Zn}$ (same as $\mathrm{Zn}-\mathrm{Eu}$ ), showing a larger spatial distribution of the cationic sub-lattice compared to $\mathrm{Zn}$.

$f_{\mathrm{Eu}-\mathrm{Eu}}$ at the expense of $f_{\mathrm{Eu}-\mathrm{Zn}}$ means that on average, the Eu atoms got more assembled, as expected from the formation of $c-\mathrm{Eu}_{2} \mathrm{O}_{3}$ particles, from $700{ }^{\circ} \mathrm{C}$. This does not rule out that, at the same time, fewer, less assembled clusters may form, such as $\mathrm{Eu}-\mathrm{Zn}_{\text {vac.-}}$-Eu clusters within the $\mathrm{ZnO}$ grains.

Figure $6 \mathrm{~b}$ shows the interatomic distances between Eu-Eu and Eu-Zn atom pairs, ranging from $3.3 \AA$ to $4.2 \AA$. This distribution of metal-metal distances in Eu local environment is larger (ca. $0.9 \AA$ ) compared to the distribution of metal-metal distances in Zu local environment (ca. $0.2 \AA$, ranging from $3.2 \AA-3.4 \AA$ ). Such large disorder in the mixed cation sub-lattice around $\mathrm{Eu}^{3+}$ ions explains the more prominent dampening effects observed for $\mathrm{Eu}^{-\mathrm{L}_{3}} \chi(R)$ (figure $5 \mathrm{~b}$ ), compared to $\mathrm{Zn}-\mathrm{K} \chi(R)$ (Figure $3 \mathrm{~b}$ ). The Eu-Eu distances decreased gradually in the temperature regime 600 to $900{ }^{\circ} \mathrm{C}$, approaching their ideal values in bulk $c-\mathrm{Eu}_{2} \mathrm{O}_{3}$. Similar trends were observed for $\mathrm{Zn}-\mathrm{Eu}$ and longer $\mathrm{Zn}-\mathrm{O}$ distances in Figure $4 b$.

General features of the overall structure. The large ionic radius difference between $\mathrm{Zn}^{2+}$ - and $\mathrm{Eu}^{3+}$ ions should render Eu incorporation at ideal $\mathrm{Zn}$ lattice sites or interstices in the $h$-ZnO structure energetically unfavourable. The Zn-K EXAFS data showed a close to unchanged $h$-ZnO (undoped) structure upon doping with as high amounts as $5 \% \mathrm{Eu}$. Thus, this is corroborated by the XRD data showing a very small increase of ca. $0.4 \%$ in $\mathrm{ZnO}$ unit cell volume. This conforms to a structure with small Eu-oxide clusters, not easily detected with XRD and TEM, residing in cavities within the $\mathrm{ZnO}$ crystals. The Eu EXAFS showed very unusual low Eu oxygen coordination numbers close to five for samples heated at $200-700{ }^{\circ} \mathrm{C}$. At higher synthesis temperatures the Eu $\mathrm{CN}$ increased to approach six for the $900{ }^{\circ} \mathrm{C}$ sample, in line with a phase separation forming $c-\mathrm{Eu}_{2} \mathrm{O}_{3}$.observed experimentally. The 
local Eu-O coordination environments indicated a wide distribution of bond-lengths in all cases. For the higher temperatures, this is likely due to the presence of two phases; $\mathrm{ZnO}: \mathrm{Eu}$ and $c-\mathrm{Eu}_{2} \mathrm{O}_{3}$, while for the lower temperature samples, it points towards the presence of Eu-oxide clusters, highly disordered in bond lengths and angles, as well as very low Eu coordination numbers with for $\mathrm{Eu}^{3+}$ ions. The ca. 1:1 ratio of Eu-Eu and Eu-Zn pairs, found for the temperature range $200-700{ }^{\circ} \mathrm{C}$, points towards small clusters in the range of 4 to $8 \mathrm{Eu}$ atoms, considering that edge and face sharing $\mathrm{Eu}\left(\mathrm{O}_{2}\right) \mathrm{Zn}$ and $\mathrm{Eu}\left(\mathrm{O}_{3}\right) \mathrm{Zn}$ bridges that could compensate for central Eu atoms being bridged only to Eu atoms, are highly unlikely for charge separation and bonding reasons. This fits the fact that even with a concentration as high as 5 at $\%$ of the strongly x-ray and electron scattering Eu atoms, there were no clear XRD peaks observed and no clusters easily detected in TEM imaging for the $600{ }^{\circ} \mathrm{C}$ sample being a pure oxide. These clusters should therefore be very small and aperiodic in nature. Another consequence is that with Eu-doping as high as $5 \% \mathrm{Eu}$, there should only be ca. 1-2 $\mathrm{nm}$ of $\mathrm{ZnO}$ between the Eu-clusters, when having an even distribution of Eu clusters in sizes small enough not to be observed with XRD or TEM. Based on the composition, each of the ca. $10 \mathrm{~nm}$ sized $\mathrm{ZnO}$ crystals should contain ca. $1100 \mathrm{Eu}$ and $22000 \mathrm{Zn}$ atoms. This corresponds ca. 150-300 Eu8 or Eu4 clusters, and implies that there is ca. 1-2 nm (3-4 $\mathrm{ZnO}_{4}$ tetrahedra) of $\mathrm{ZnO}$ between the clusters, if evenly distributed. It can also be observed, in line with previous XRD, TEM and XPS studies,(46) that at temperatures from $700{ }^{\circ} \mathrm{C}$, phase separation of the Eu-doped $\mathrm{ZnO}$ nanosponges into $\mathrm{ZnO}$ with low, or no $\mathrm{Eu}$ content and $c-\mathrm{Eu}_{2} \mathrm{O}_{3}$ took place. This, likely as a consequence of a metastable nature of the cluster structures.

\subsection{DFT modelling of the ZnO:Eu structure}

A few theoretical studies on Eu-doping in $\mathrm{ZnO}$ can be found in the literature.(64-70) Yet, to the best of our knowledge, the possibility of Eu-oxide cluster formation, as observed here, has not been considered so far. Most of these theoretically calculated structures considered single atom doping,(64-68) isovalent doping, $(69,70)$ or doping associated with point defects at $\mathrm{Zn}$ sites (substitutional). However, the much larger ionic radius ( 84 versus $60 \mathrm{pm}$ ) of 4 -coordinated $\mathrm{Eu}^{3+}$ ions in the $\mathrm{Zn}^{2+}$-ion position in the $h-\mathrm{ZnO}$ host structure is far from optimal for $\mathrm{Eu}^{3+}$ ions as substitutional defects.

To gain insight into the $\mathrm{ZnO}: 5 \% \mathrm{Eu}$ structures, a series of theoretical total energy evaluations at a constant Eu-doping concentration corresponding to $4.17 \mathrm{at} \% \mathrm{Eu}$, with respect to the total number of metal-ions, were performed using DFT. In the evaluation, one $\mathrm{Zn}^{2+}$ vacancy per two $\mathrm{Eu}^{3+}$ ions was added to achieve charge neutrality. 23 cases of $\left(\mathrm{Eu}_{2} \mathrm{O}_{3}\right)_{\mathrm{x}}$ clusters with $x=1,2$, or 4, depending on super-cell size, all with the same overall doping concentration, were embedded in the host lattice were compared. A summary of the overall energetic and structural information in the form relative total energies for a representative set of Eu-doping configurations, are given in Figure 7. Structure 1, set as reference point for the cluster comparisons in Figure 7, represents a structure with the $\mathrm{Eu}^{3+}$ ions and the accompanied $\mathrm{Zn}^{2+}$-ion vacancies were randomly distributed, within the $\mathrm{ZnO}$ structure. 
The first cluster structures, represented by structure 2, compared $\mathrm{Eu}^{3+}$-dimer formation, i.e. $\mathrm{Eu}^{3+}-\mathrm{Zn}_{\text {vac. }}-\mathrm{Eu}^{3+}$ clusters, is as previously discussed.(48) This step resulted in a huge energy gain of 1.06 $\mathrm{eV}$ per cluster. Structure 3 to 5 in Figure 7 show examples of further clustering with different cases of $\left(\mathrm{Eu}^{3+}-\mathrm{Zn}_{\text {vac. }}-\mathrm{Eu}^{3+}\right)_{2}$ clusters that were formed with 4 or $8 \mathrm{Eu}$ atoms. As can be seen, further clustering is not as energetically favourable as the first $\left(\mathrm{Eu}^{3+}-\mathrm{Zn}_{\mathrm{vac}}-\mathrm{Eu}^{3+}\right)$, but still sizeable. The largest energy gain found in this study for $\left(\mathrm{Eu}^{3+}-\mathrm{Zn}_{\text {vac. }}-\mathrm{Eu}^{3+}\right)_{2}$ formation is $0.3 \mathrm{eV} /\left(\mathrm{Eu}^{3+}-\mathrm{Zn}_{\text {vac. }}-\mathrm{Eu}^{3+}\right)$ cluster.

The energy gain when forming the simplest $\mathrm{Eu}^{3+}-\mathrm{Zn}_{\mathrm{vac}}-\mathrm{Eu}^{3+}$ cluster for a local charge neutrality is thus large, but the large ionic radius of the $\mathrm{Eu}^{3+}$ ion, even in its smallest four-coordination form should be hard to accommodate and align with the $\mathrm{ZnO}$ lattice, even if the $\mathrm{Eu}^{3+}$ ions can be displaced using the void of the $\mathrm{Zn}^{2+}$ vacancy. Therefore, there should be strain on the $\mathrm{ZnO}$ lattice reducing its stability compared to the larger Eu-oxide clusters involving 4-8 $\mathrm{Eu}^{3+}$ ions.

It thus seems that $\left(\mathrm{Eu}_{2} \mathrm{O}_{3}\right)_{\mathrm{x}}$ clusters with $\mathrm{x}=2-4$ being similar in energy are optimal in providing a possibility to include the $\mathrm{Eu}^{3+}$ ions, while keeping the $\mathrm{ZnO}$ structure fairly intact. Here the ability for the $\mathrm{Eu}^{3+}$ ions, having a spherical outer orbital shell, makes it possible to adopt more or less any number of oxygen ligands, bond-lengths and spatial distribution of bonds, to achieve as suitable electronic saturation by ligand electron donation, as possible. This finding is supported by some tests with even higher x-values. A restriction in optimal size might stem from an optimal Lewis acid-base interaction between the $\mathrm{ZnO}$ and $\mathrm{Eu}_{2} \mathrm{O}_{3}$ where an overall electron donation from $\mathrm{Eu}_{2} \mathrm{O}_{3}$ to the $\mathrm{ZnO}$ is expected.

Comparison with experimental data. The $\mathrm{ZnO}: 5 \% \mathrm{Eu}$ sponge obtained at $600{ }^{\circ} \mathrm{C}$ showed no organic or carbonate residues, and nor any detectable phase separation, and is therefore the most intriguing and interesting to describe, and fits the pure non-phase-separated oxide DFT modelled here.

As discussed above, the EXAFS data indicated a close to unchanged $\mathrm{ZnO}$ lattice upon doping with the large, alio-valent $\mathrm{Eu}^{3+}$ ions forming small oxide-clusters within the $\mathrm{ZnO}$ crystals. The $\mathrm{Eu}^{3+}$ ions in these clusters were coordinated by a very unusual low average of ca. 5.1 oxygens, and showed a wide distribution of bond-lengths and directions. As shown above, the EXAFS data fitted well the XRD, TEM and XPS data where the TEM showed that the Eu-oxide clusters had to be small and non-periodical not to be easily observed and the XRD data showed an approximate increase in unit cell volume of ca. $0.4 \%$ for the $5 \%$ Eu doping. $(48,49)$

This means that complementary, and in parts, much uncommon experimental results are present that can be used to verify the validity of theoretical DFT-based structural description of the Eu-cluster structures within the $\mathrm{ZnO}$ crystals.

Thus, the 23 theoretical structures including different Eu-cluster structures, and one un-doped $\mathrm{ZnO}$ structure (structure 20 ), could be judged not only by their relative energies $(\Delta \mathrm{E})$, but also on the experimentally obtained Eu-doped $\mathrm{ZnO}$ unit-cell volume relative to $\mathrm{ZnO}(\Delta \mathrm{V} \%)$, Eu-to-oxide coordination number $(\mathrm{CN})$, Eu-Eu distances $(\mathrm{d}(\mathrm{Eu}-\mathrm{Eu})(\AA))$. Figure 8, gives these data arranged in total energy order for a comprehensive overview of these parameters. 
Formation energy, coordination and $\mathrm{ZnO}$ :5\%Eu unit cell volume. The structures ordered in relative energy $(\Delta \mathrm{E})$ start from structure 23 , which represents a random distribution of $\mathrm{Eu}^{3+}$ ions and $\mathrm{Zn}^{2+}$-vacancies which is $0.43 \mathrm{eV}$ above the highest energy $\left(\mathrm{Eu}_{2} \mathrm{O}_{3}\right)_{1}$ cluster, 21, having paired $\mathrm{Eu}^{3+}$ ions flanking a $\mathrm{Zn}^{2+}$ vacancy. The clusters 13 to 21 have different spatial orientations of the $\left(\mathrm{Eu}_{2} \mathrm{O}_{3}\right)_{1}$ clusters within the $\mathrm{ZnO}$ structure. It can be seen that the $\Delta \mathrm{E}$ for these clusters drop differ little. It can be noted that all these clusters, except the two with the lowest $\Delta \mathrm{E}$ have $\mathrm{Eu}^{3+}$ ions with all $\mathrm{CN} 4$. Similarly, the $\mathrm{ZnO} \Delta \mathrm{V}_{\mathrm{ZnO}}$ is roughly $1.8 \%$, for the $\mathrm{CN} 4$ based clusters, while the two lowest clusters in $\Delta \mathrm{E}, 13$ and 14 , having average $\mathrm{CN}$ of 4.5 have, a lower $\Delta \mathrm{V}_{\mathrm{ZnO}}$ of $1.0-1.3 \%$. It thus indicates, as expected, that it is hard to accommodate the large $\mathrm{Eu}^{3+}$ ions at positions close to the tetrahedral $\mathrm{Zn}^{2+}$ lattice positions, even when there is a metal vacancy nearby in small clusters. The size mismatch leads to an increased $\mathrm{ZnO}$ unit cell volume and high formation energy. Some relaxation in the $\mathrm{ZnO}$ structure can be seen in clusters containing higher $\mathrm{Eu} \mathrm{CN}$ of 4.5 (structure 11) and 5 (structure 9) yielding $\Delta \mathrm{E}$ comparable with the highest energy clusters with 4 and $8 \mathrm{Eu}^{3+}$ ions. However, these clusters show very high $\Delta \mathrm{V}_{\mathrm{ZnO}}$ of 1.5$1.5 \%$, not compatible with the experimental results.

Further clustering of $\left(\mathrm{Eu}_{2} \mathrm{O}_{3}\right)_{1}$ pairs to $\mathrm{Eu} 4$ and $\mathrm{Eu} 8$ clusters led to a distinct drop in formation energy by $0.30 \mathrm{eV}$. As for the $\left(\mathrm{Eu}_{2} \mathrm{O}_{3}\right)_{1}$ clusters, the $\left(\mathrm{Eu}_{2} \mathrm{O}_{3}\right)_{\mathrm{x}}(\mathrm{x}=2$ and 4$)$ clusters with different spatial arrangements showed a range of formation energies from $1.03 \mathrm{eV}$ below the reference structure, 22 , to the three lowest values found for structure 0,1 and 2 at 1.30-1.38 eV below the reference structure. This

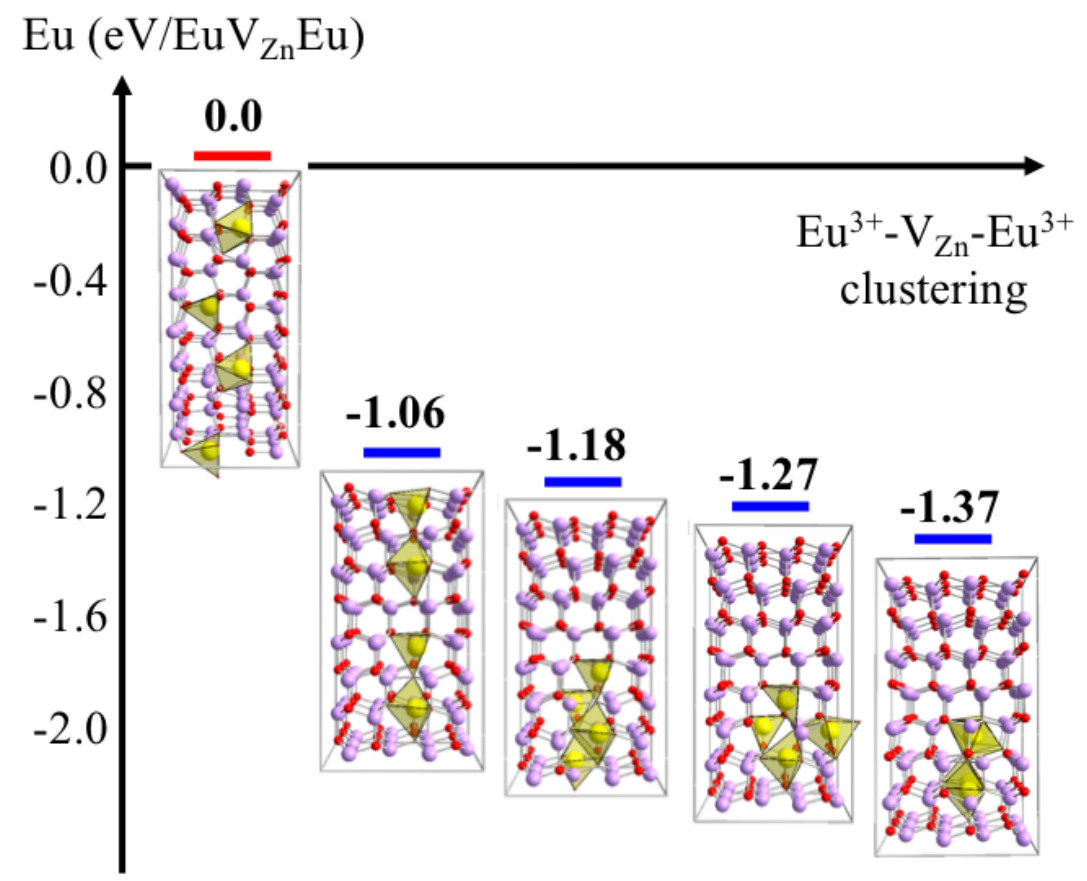

Figure 7. Relative formation energies of $\left(\mathrm{Eu}^{3+}-\mathrm{Zn}_{\mathrm{vac}}-\mathrm{Eu}^{3+}\right)$ structures with respect to a random distribution of $\mathrm{Eu}^{3+}$ ions and $\mathrm{Zn}^{2+}$ vacancies.

is a sizeable energy difference to the Eu4 and Eu8 clusters of up to $0.35 \mathrm{eV}$ or ca. $30 \mathrm{kJmol}^{-1}$, although the difference to the reference structure which is similar to the sometimes discussed random Eu doping 
in $\mathrm{Zn}$-ion positions is very substantial with $1.38 \mathrm{eV}$, or $133 \mathrm{kJmol}^{-1}$. It can be observed that of the three lowest formation energies found for structure 0, 1 and, 2 the two first are Eu4 clusters and the latter, an Eu8 cluster. The other Eu8 cluster analysed, structure 7, is found in the midst of the Eu4 clusters, which indicates that the Eu4 and 8 clusters are generally rather similar in $\Delta \mathrm{E}$ and at clearly lower formation energies than smaller clusters. This also fits the fact that it has been hard to reveal the Eu-clusters with conventional HR TEM. These three clusters, are also the ones fitting the experimental data best with $0.58-0.68 \% \Delta \mathrm{V}_{\mathrm{ZnO}}$, compared to ca. $0.4 \%$ determined by $\mathrm{XRD}$, and $\mathrm{Eu} \mathrm{CN}$ of $4.87-4.94$, compared to ca. 5.1 determined by EXAFS in this work. Such small volume changes and differences in average Eu $\mathrm{CN}$ are hard to determine experimentally, and the theory fits experimental data within a judged real error.

It can be observed that these three lowest energy clusters differ amongst the Eu4 and Eu8 clusters in having a higher $\mathrm{Eu} C N$ and higher $\Delta \mathrm{V}_{\mathrm{ZnO}}$. It could be speculated that low Eu $\mathrm{CN}$ is hard to combine with the $\mathrm{ZnO}$ structure containing the much smaller $\mathrm{Zn}^{2+}$-ion and that a consequence of low $\mathrm{CN}$ is an increased $\mathrm{ZnO}$ unit cell volume.

Eu-Eu distances. Examples of coordination figures from the literature showing short to long Eu-Eu distances in oxides and related alkoxide structures are shown in Figure 8. The $c-\mathrm{Eu}_{2} \mathrm{O}_{3}$ expelled from the $\mathrm{ZnO}: \mathrm{Eu}$ crystals upon heating at higher temperatures have all six-coordinated $\mathrm{Eu}^{3+}$ ions and all four-coordinated oxygens.(59) The Eu-Eu distances in this structure are close to $3.60 \AA$. There also exists the high temperature polymorph $m-\mathrm{Eu}_{2} \mathrm{O}_{3}$ above $1200{ }^{\circ} \mathrm{C}$, which has a mix of six- and sevencoordinated $\mathrm{Eu}^{3+}$ ions and a large variation of $\mathrm{Eu}$ coordination figures and $\mathrm{Eu}-\mathrm{Eu}$ distances. The $\mathrm{Eu}-\mathrm{Eu}$ distances in this oxide range from 3.33 to $5.49 \AA$, with the shortest distance found between $\mathrm{Eu}^{3+}$ ions in face sharing $\mathrm{Eu}\left(\mathrm{O}_{3}\right) \mathrm{Eu}$ pairs $(3.33 \AA$ ) and the longest for strait $\mathrm{Eu}(\mathrm{O}) \mathrm{Eu}$ bonds, being $5.09 \AA$ with $\mathrm{CN} 6$ $\mathrm{Eu}^{3+}$ ions and $5.49 \AA$ between $\mathrm{CN} 7 \mathrm{Eu}^{3+}$ ions. Another example of close to linear $\left(170^{\circ}\right) \mathrm{Eu}-\mathrm{O}-\mathrm{Eu}$ bonds with $\mathrm{CN} 6 \mathrm{Eu}^{3+}$ ions is found in the molecular Eu-oxo-alkoxide, $\mathrm{Eu}_{5} \mathrm{O}\left(\mathrm{OPr}^{\mathrm{i}}\right)_{13}$, which shows EuEu distances of 4.82-4.87 A.(71) This molecule also contains close to $90^{\circ} \mathrm{Eu}-\mathrm{O}-\mathrm{Eu}$ angles in the base plane of this pyramidal molecule, which results in very short Eu-Eu distances of down to 3.42-3.43 $\AA$. These distances set the expected minimum and maximum Eu-Eu distances expected for CN6 and CN7 $\mathrm{Eu}^{3+}$ ions in the present Eu-oxide clusters. For lower coordination numbers, even shorter distances could be considered, but the $\mathrm{Eu}^{3+}-\mathrm{Eu}^{3+}$ electronic repulsion should make it energetically costly to form.

It can be observed that the Eu-Eu distances in the 23 clusters studied are within reasonable minimum and maximum values, as discussed above. The Eu8 cluster in structure 7, has an Eu-Eu distance that could be too short, although it is borderline, considering the possibility of lower Eu CN than in the literature examples.

The three lowest formation energy clusters show Eu-Eu distances in the range 3.42 to $4.75 \AA$, which are reasonable distances and fit the EXAFS data very well. These clusters are also small enough to have close to a 1:1 ratio of Eu-Eu and Eu-Zn pairs, as given by the EXAFS data. Considering the low 


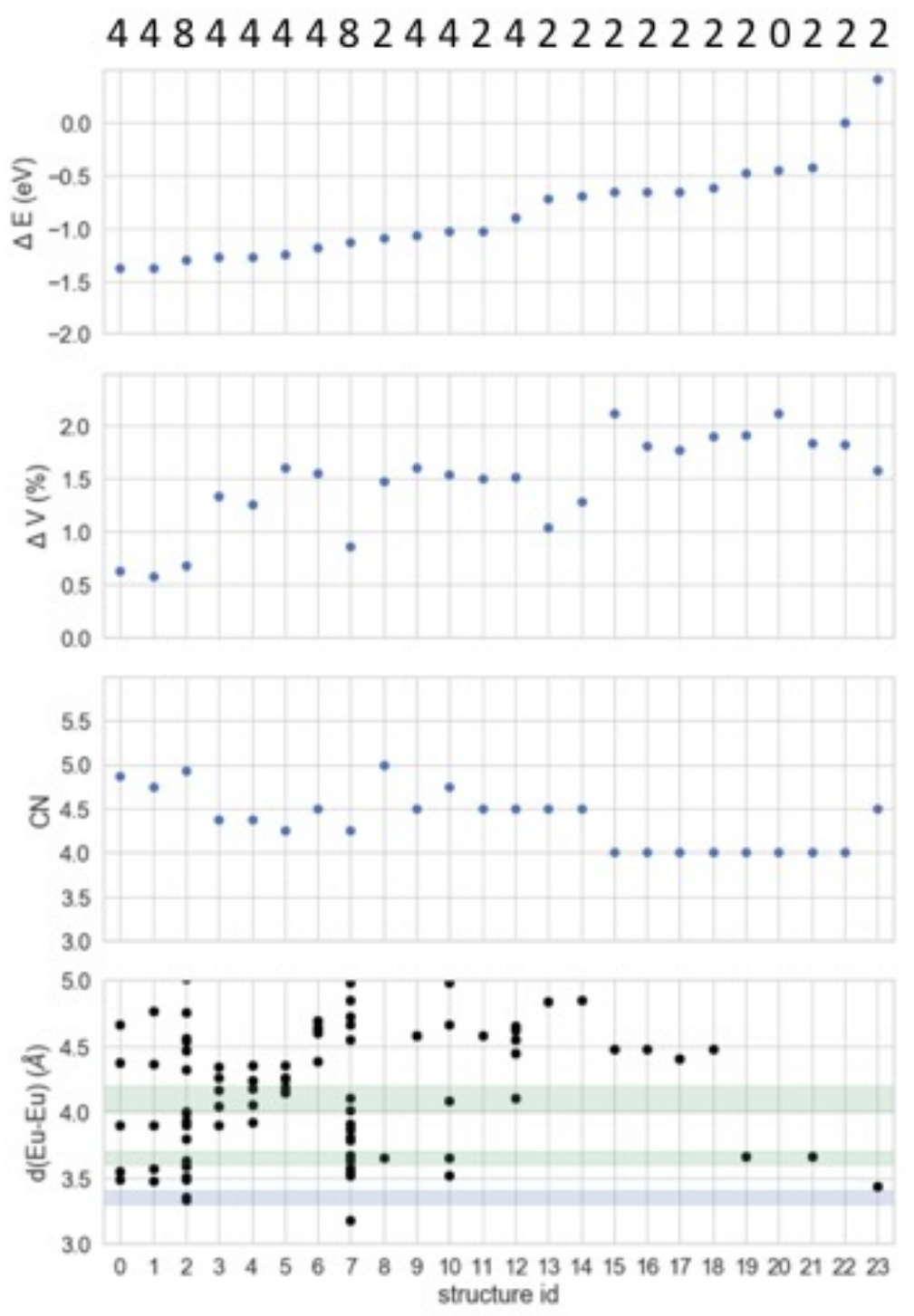

Figure 8. Theoretical structures of the composition $\mathrm{ZnO}: 4.17 \% \mathrm{Eu}$ with europium cluster compositions based on $\left(\mathrm{Eu}_{2} \mathrm{O}_{3}\right)_{\mathrm{x}}$ pairs embedded in $\mathrm{ZnO}$ with $\mathrm{x}=1,2$ and 4 . The structures are ordered in total formation energy per $\mathrm{Eu}_{2} \mathrm{O}_{3}$ cluster $(\Delta \mathrm{E}, \mathrm{eV})$ relative to a random ordering of $2 \mathrm{Eu}^{3+}$-ions and one $\mathrm{Zn}^{2+}$ vacancy for charge neutralisation. The $\mathrm{ZnO}$ unit-cell volume change versus un-doped $\mathrm{ZnO}(\Delta \mathrm{V}, \%)$, average $\mathrm{Eu}$ coordination number $(\mathrm{CN})$ and Eu-Eu distances (d(Eu-Eu), $\AA$ ) are also given for each structure. (Structure 20 is an undoped $\mathrm{ZnO}$ structure)

difference in energy between the Eu4 and Eu8 clusters, and the energy leap to the Eu2 clusters, it is not unlikely that there is a distribution of cluster sizes with even numbers of Eu atoms, in the range 4-8 Eu atoms. It is therefore interesting to study their structures in more detail.

Eu-oxide cluster structures. In Figure 9, examples of the low energy structures 0 and 2, with Eu4 and Eu8 clusters respectively, shown along with a structure containing Eu2 clusters. The latter 
Eu2 cluster

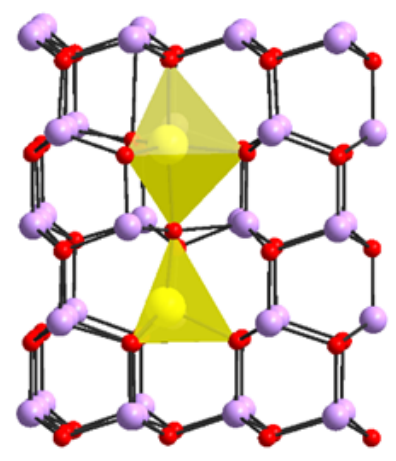

Eu4 cluster
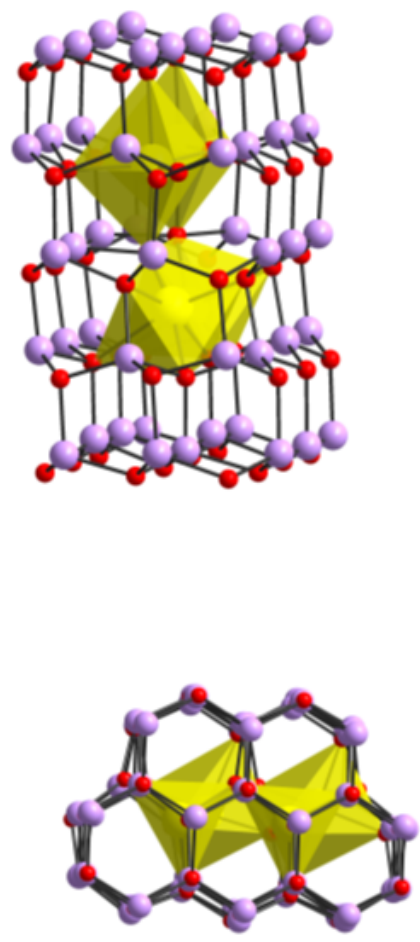

Eu8 cluster
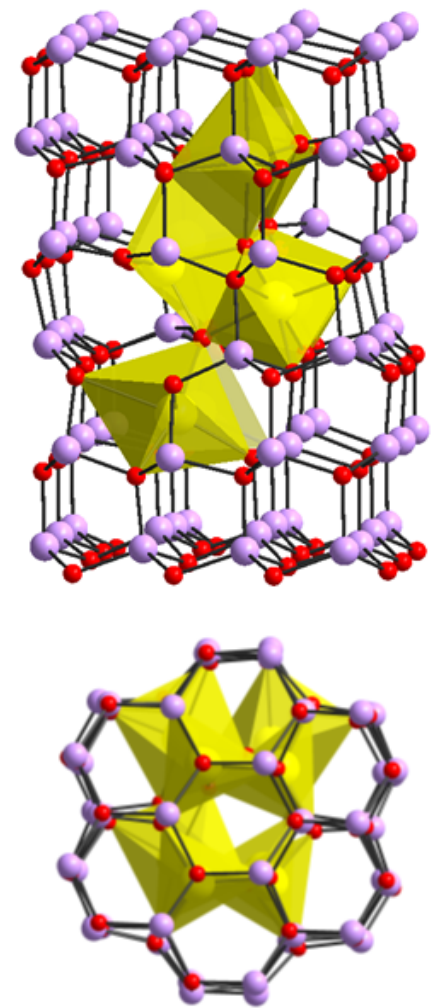

Figure 9. Structures of viewing the $\mathrm{ZnO}$ cell from (upper row) the a,b-direction and (lower row) down the c-direction: (left) a low energy Eu2 cluster with a $\mathrm{CN}$ of 4.5, (mid) a low energy Eu4 cluster and (right) an Eu8 cluster.

structure having the two $\mathrm{Eu}^{3+}$ ions aligned along the $\mathrm{ZnO}$ c-axis with an average $\mathrm{Eu} \mathrm{CN}$ of 4.5 has a relatively low formation energy within the group of $\mathrm{Eu} 2$ containing $\mathrm{ZnO}$ structures.

It can be observed that in all cases, the Eu-oxide clusters are surrounded by an almost intact $\mathrm{ZnO}$ lattice. The cage structures, built from $\mathrm{ZnO}$ tetrahedra around the Eu-oxide clusters, are in some ways similar clathrates of water and inclusion compounds such as MOF:s, enclosing larger atoms or molecules in a crystalline host. However, when looking closer there are some small distortions in the $\mathrm{ZnO}$ lattice close the clusters which causes the differences in $\mathrm{ZnO}$ unit cell volume and total formation energy of the Eu-doped $\mathrm{ZnO}$ structures. It was also be observed that all $\mathrm{Zn}$-ions were tetrahedrally coordinated to oxygens bonded to other $\mathrm{Zn}$ or $\mathrm{Eu}^{3+}$ ions in a cluster. This indicates that lowering of the energy in these structures is dominated by providing the $\mathrm{ZnO}$ structure optimal coordination and distances. But, with all $\mathrm{Eu}^{3+}$ ions connecting to a $\mathrm{Zn}$-ion, there is also close to optimal conditions for electronic donation from the $\mathrm{Eu}^{3+}$ ion coordinated Lewis basic oxygens to the more Lewis acidic $\mathrm{Zn}^{2+}-$ ions which should provide stabilisation.

At the connection between the Eu-oxide clusters and the host $\mathrm{ZnO}$, there are no dangling bonds from unsaturated three-coordinated $\mathrm{Zn}$ tetrahedral found. Instead, there are $\mathrm{Zn}$-O-Eu bonds with the $\mathrm{Zn}$ - 
O tetrahedron rather intact in its typical coordination figure, as was also given experimentally by EXAFS.

There are some common features in how the lowest energy clusters of different sizes are embedded in the $\mathrm{ZnO}$ structure. From Figure 9, it can be observed when viewing along the $\mathrm{ZnO}$ c-axis, the clusters prefer to be aligned along the c-axis and end with a trigonal bipyramidal Eu-ion, connecting to the $\mathrm{Zn}$ atom in the 0001 plane through at the apex, and to the $000-1$ plane, via the triangular face of a tetrahedron or octahedron.

The Eu2 clusters with the lowest formation energy are aligned along the $\mathrm{ZnO}$ c-axis with the $\mathrm{Eu}^{3+}$ ions making use of the $\mathrm{Zn}$-ion vacancy volume to form a bond to the other Eu-ion creating a trigonal bipyramid in a suitable size to fit the $\mathrm{ZnO}$ structure, as well as a tetrahedron positioned to fit the $\mathrm{ZnO}$ structure through a trigonal face. This leaves an average $\mathrm{Eu} \mathrm{CN}$ of 4.5 and allows the large $\mathrm{Eu}^{3+}$ ions to move closer to the vacancy volume and form a trigonal bipyramid with short equatorial Eu-O bonds and long axial bonds fitting the smaller $\mathrm{ZnO}$ structure. This differ from doping modes in structures with all tetrahedral $\mathrm{Eu}^{3+}$ ions which are higher in formation energy as can be observed in Figure 8.

The Eu4 and Eu8 clusters have similar build-ups with $\mathrm{Eu}^{3+}$ ions coordinated by 4, 5, and 6 oxygens forming strongly distorted coordination polyhedra. This allows the $\mathrm{Eu}^{3+}$ ions flexibility in forming suitable bonds to the relatively stiff $\mathrm{ZnO}$ cage, while optimising the charge transfer between $\mathrm{Eu}^{3+}$ ions and oxygens within the cluster through highly distorted and varied Eu-oxygen polyhedral, allowed by the spherical outer shell. The wide range of coordination numbers, bond-lengths, and directions fit the broad peaks observed by EXAFS.

\subsection{Optical properties}

$\mathrm{The}^{\mathrm{Eu}^{3+}}$ ion is well-known for its excellent optical properties that can be leveraged into technological applications or be used to probe the dopant ion's local structural environment in a host lattice.(72) Therefore, the optical properties of the Eu-doped $\mathrm{ZnO}$ nanosponges were investigated by steady-state and time-resolved excitation, and emission spectroscopy. As representative samples, nanosponges obtained at 400,600 , and $800{ }^{\circ} \mathrm{C}$ were investigated. While the $400{ }^{\circ} \mathrm{C}$ sample, which contains residual

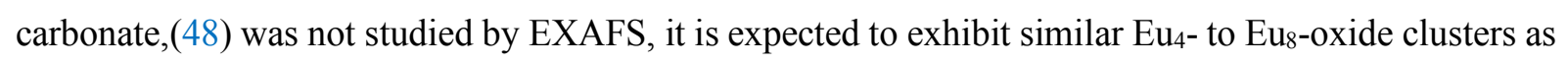
observed by EXAFS for the 200 and $600{ }^{\circ} \mathrm{C}$ samples. As mentioned above, the $600{ }^{\circ} \mathrm{C}$ sample is of particular interest as it is free from organic or carbonate residues, while showing no detectable phase separation into $\mathrm{ZnO}$ and $c$ - $\mathrm{Eu}_{2} \mathrm{O}_{3}$. In contrast, $c-\mathrm{Eu}_{2} \mathrm{O}_{3}$ was separated as secondary crystalline phase in the $800{ }^{\circ} \mathrm{C}$ sample.

Figure 10a-c shows excitation spectra monitoring the characteristic $\mathrm{Eu}^{3+5} \mathrm{D}_{0} \rightarrow{ }^{7} \mathrm{~F}_{2} f-f$ transition at 614 $\mathrm{nm}$ (in lighter colours) and the $\mathrm{ZnO}$ matrix emission at 545 or $550 \mathrm{~nm}$ (in darker colours). Irrespective the monitored emission and synthesis temperature, the recorded excitation spectra exhibit two regions of distinct spectral features, namely below and above $375 \mathrm{~nm}$. At wavelengths shorter than $375 \mathrm{~nm}$, a broad band arises at ca. $330 \mathrm{~nm}$, the intensity of which strongly increases for higher temperatures of 600 

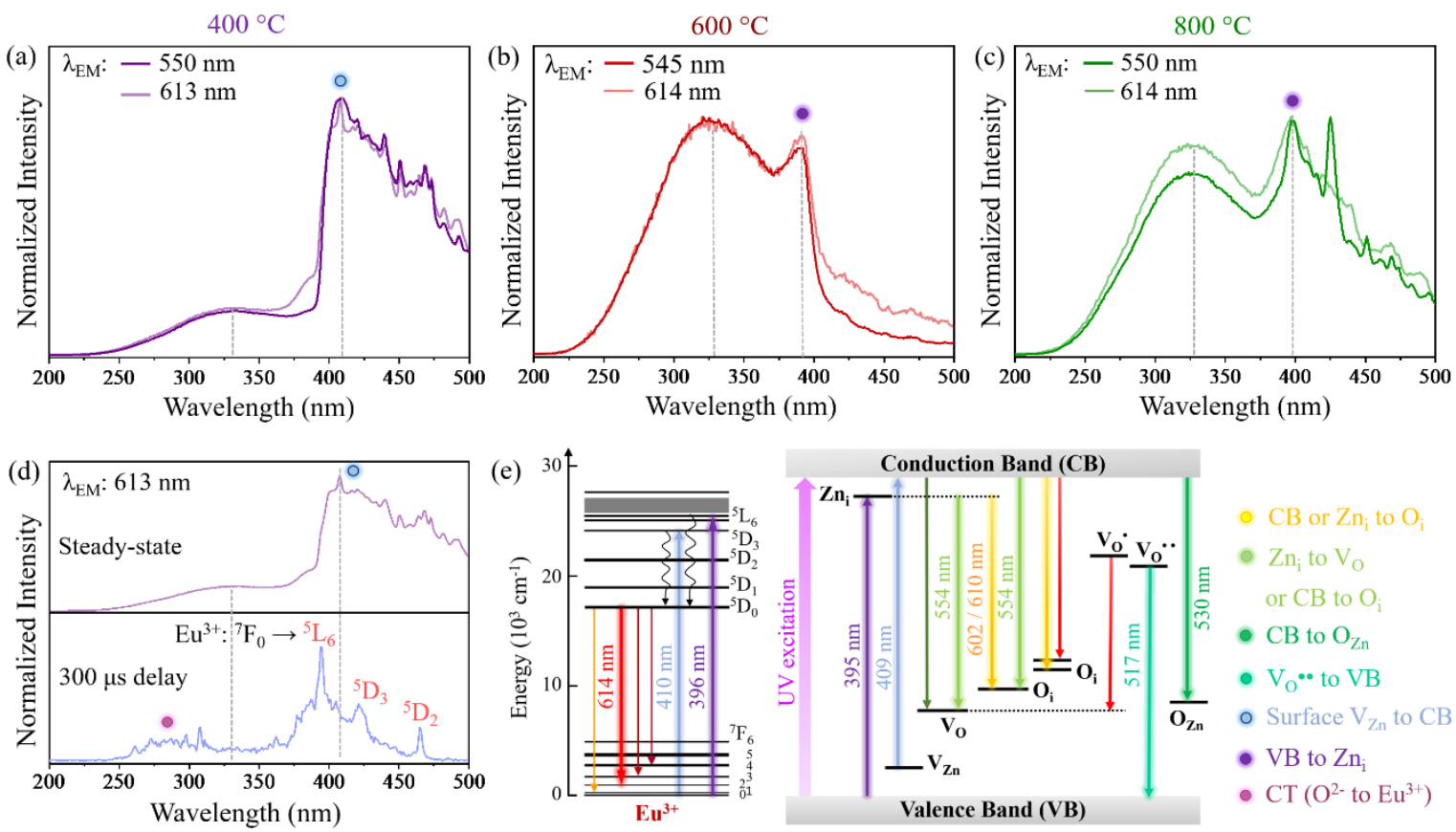

$\mathrm{CB}$ or $\mathrm{Zn}_{\mathrm{i}}$ to $\mathrm{O}_{\mathrm{i}}$

$\mathrm{Zn}_{\text {i }}$ to $\mathrm{V}_{0}$

or $\mathrm{CB}$ to $\mathrm{O}$

- $\mathrm{CB}$ to $\mathrm{O}_{\mathrm{Zn}}$

- $\mathrm{V}_{\mathrm{O}} \bullet$ to $\mathrm{VB}$

- Surface $\mathrm{V}_{Z \mathrm{n}}$ to $\mathrm{CB}$

- VB to $\mathrm{Zn}_{\mathrm{i}}$

- $\mathrm{CT}\left(\mathrm{O}^{2-}\right.$ to $\left.\mathrm{Eu}^{3+}\right)$

Figure 10. (a-c) Steady-state excitation spectra of $\mathrm{ZnO}: \mathrm{Eu}$ nanosponges obtained at 400,600 , and $800{ }^{\circ} \mathrm{C}$, respectively, showing different spectral profiles stemming from various $\mathrm{ZnO}$ defect types. (d) Bottom: Time-resolved excitation spectrum of the sample obtained at $400{ }^{\circ} \mathrm{C}$, showing $\mathrm{Eu}^{3+} f-f$ excitation bands after a delay of $300 \mu \mathrm{s}$. Top: Steady-state spectrum added to highlight the contribution of $\mathrm{ZnO}$ excitation on the overall spectral features. (e) Energy level scheme showing the $\mathrm{Eu}^{3+}$ energy levels (left) (72) and ZnO defect levels (middle) in addition to valence $(\mathrm{VB})$ and conduction band $(\mathrm{CB})\left(\mathrm{O}_{\mathrm{Zn}}\right.$ : anti-site oxygen atoms, $\mathrm{V}_{\mathrm{Zn}}$ : zinc vacancies, $\mathrm{V}_{\mathrm{O}}$ : oxygen vacancies, $\mathrm{Zn}_{\mathrm{i}}$ : interstitial zinc atoms, $\mathrm{O}_{\mathrm{i}}$ : interstitial oxygen atoms, $\mathrm{V}_{\mathrm{O}}{ }^{\bullet}$ and $\mathrm{V}_{\mathrm{O}} \bullet \bullet$ : singly and doubly ionized oxygen vacancies, $\mathrm{CT}$ : charge transfer). The attribution of the main excitation (and emission, Figure 10, vide infra) bands is given on the right.

and $800{ }^{\circ} \mathrm{C}$. Photons in the UV spectral region of the observed band have an energy high enough to excite an electron in the $\mathrm{ZnO}$ valence band (VB) to the conduction band (CB).

Analysing the spectral region above $375 \mathrm{~nm}$, the excitation profile changed significantly between the $400{ }^{\circ} \mathrm{C}$ sample on the one side (Figure 10a) and the 600 and $800{ }^{\circ} \mathrm{C}$ samples on the other (Figure 10b,c). This variation in spectral features indicates the presence of different defect states lying in the band-gap of $\mathrm{ZnO}$ (Figure 10e).(49) The sample obtained at $400{ }^{\circ} \mathrm{C}$ exhibits an excitation band at $409 \mathrm{~nm}$ (Figure 10a), which can be ascribed to an absorption from the energy level attributed to zinc vacancies $\left(\mathrm{V}_{\mathrm{Zn}}\right)$ at the crystal surface to the $\mathrm{ZnO}$ conduction band (Figure 10e).(73) Following excitation into the $\mathrm{CB}$, radiative decay to defect states related to, for instance, oxygen vacancies $\left(\mathrm{V}_{\mathrm{O}}\right)$, interstitial oxygen atoms $\left(\mathrm{O}_{\mathrm{i}}\right)$ or anti-site oxygen atoms $\left(\mathrm{O}_{\mathrm{Zn}}\right)$ can trigger the monitored green $\mathrm{ZnO}$ emission. Conversely, the excitation band at $409 \mathrm{~nm}$ was not observed for samples synthesised at 600 and $800{ }^{\circ} \mathrm{C}$, respectively (Figures 10b,c). Instead, bands at 392 and $398 \mathrm{~nm}$ likely stemming from transitions between the $\mathrm{ZnO}$ valence band and interstitial zinc atoms $\left(\mathrm{Zn}_{\mathrm{i}}\right)$ were observed in these samples.(73) Subsequent 
radiative decay from $\mathrm{Zn}_{\mathrm{i}}$ to $\mathrm{V}_{\mathrm{O}}$ defect states is one possible pathway generating the monitored green $\mathrm{ZnO}$ emission. It is worth mentioning, that the precise assignment of the excitation and emission (vide infra) bands resulting from the different type of defects induced in the $\mathrm{ZnO}$ matrix is still under debate, and therefore the above attributions were suggested based on the literature and our previous spectroscopic observations for these materials.(49) Time-resolved excitation spectroscopy on the 400 ${ }^{\circ} \mathrm{C}$ sample allowed to suppress the detection of fast $\mathrm{ZnO}$-related excitation bands to monitor the $\mathrm{Eu}^{3+}$ emission at $613 \mathrm{~nm}$ as a function of the excitation wavelength after a time delay. Figure 10d (bottom) shows several $\mathrm{Eu}^{3+} f-f$ excitation bands ascribed to the ${ }^{7} \mathrm{~F}_{0} \rightarrow{ }^{5} \mathrm{~L}_{6},{ }^{7} \mathrm{~F}_{0} \rightarrow{ }^{5} \mathrm{D}_{2}$, and ${ }^{7} \mathrm{~F}_{0} \rightarrow{ }^{5} \mathrm{D}_{3}$ transitions. The lack of the weak excitation band at ca. $330 \mathrm{~nm}$ as well as the strong excitation band at $409 \mathrm{~nm}$ in the time-resolved spectrum (Figure 10d, bottom) versus their presence in the steady-state spectrum (Figure 10d, top) supports that both bands are $\mathrm{ZnO}$-related. Besides the peaks ascribed to $\mathrm{Eu}^{3+} f-f$ transitions, an additional weak broad band was observed at ca. $280 \mathrm{~nm}$. The origin of this excitation band is suggested to be a $\mathrm{Eu}^{3+} \leftarrow \mathrm{O}^{2-}$ charge transfer $(\mathrm{CT})$, whereas oxygen in the Eu-oxide clusters, formed inside the $\mathrm{ZnO}$ matrix, can transfer energy to $\mathrm{Eu}^{3+}$ ions. These broad bands have been observed in other Eu-based oxides and been attributed to the overall combination of charge transfer transitions in metal-oxygen polyhedra.(74-77)

Based on the insights gained by excitation spectroscopy, emission spectra were recorded under excitation either into the $\mathrm{ZnO}$ conduction band or at specific $\mathrm{ZnO}$ defect levels, resulting in significantly different spectral profiles for samples obtained at 400,600 , and $800{ }^{\circ} \mathrm{C}$ (Figure 10a-c). For any of the three temperatures investigated, UV excitation at ca. 330 to $350 \mathrm{~nm}$ (darker colour curves) resulted in a broad band emission centred in the green spectral region. Green $\mathrm{ZnO}$ emission is often ascribed to oxygen deficiency (i.e., $\mathrm{V}_{\mathrm{O}}$ or excess $\mathrm{Zn}^{2+}$ ions).(78) Yet, it has also been related to interstitial $\left(\mathrm{O}_{\mathrm{i}}\right)$ and anti-site $\left(\mathrm{O}_{\mathrm{Zn}}\right)$ oxygen, as it may be induced upon thermal treatment of the $\mathrm{ZnO}$ nanosponges in air. $(79,80)$ This may explain the slight blue-shift of the broad emission band for the 600 and $800{ }^{\circ} \mathrm{C}$ samples, respectively, compared to the $400{ }^{\circ} \mathrm{C}$ sample under excitation into the $\mathrm{ZnO}$ conduction band.

The sample obtained at $400{ }^{\circ} \mathrm{C}$ (Figure 11a) exhibited an additional sharp peak at $614 \mathrm{~nm}$ due to the main $\mathrm{Eu}^{3+}$ emission $\left({ }^{5} \mathrm{D}_{0} \rightarrow{ }^{7} \mathrm{~F}_{2}\right)(72)$, not present for the other samples. Changing the excitation wavelength to match the most intense excitation band for $\mathrm{ZnO}$ defect levels in the $400{ }^{\circ} \mathrm{C}$ sample, i.e., $409 \mathrm{~nm}$ (surface $\mathrm{V}_{\mathrm{Zn}}$ to conduction band, lighter colour curve), sharp emission bands due to $\mathrm{ZnO}$ defect states - including oxygen-related defect states in the 500 to $600 \mathrm{~nm}$ spectral range - in addition to the ${ }^{5} \mathrm{D}_{0} \rightarrow{ }^{7} \mathrm{~F}_{2} \mathrm{Eu}^{3+}$ emission were observed (Figure 11a). Time-resolved emission spectroscopy of the $\mathrm{Eu}^{3+}$ emission under $409 \mathrm{~nm}$ excitation (Figure 11d, bottom) further confirmed the characteristic $\mathrm{Eu}^{3+}$ emission bands, whereas suppression of the $\mathrm{ZnO}$ emission clearly unveiled the emission bands characteristic for the $\mathrm{Eu}^{3+5} \mathrm{D}_{0} \rightarrow{ }^{7} \mathrm{~F}_{\mathrm{J}}(\mathrm{J}=0,1,2,3$, and 4) transitions. The lack of spectral fine-structure in these bands can be caused by structural disorder (81) around the Eu ions, induced by, for instance, carbonate residues, $\mathrm{ZnO}$-related defects and Eu-oxide clusters that are expected to be formed (e.g., at 

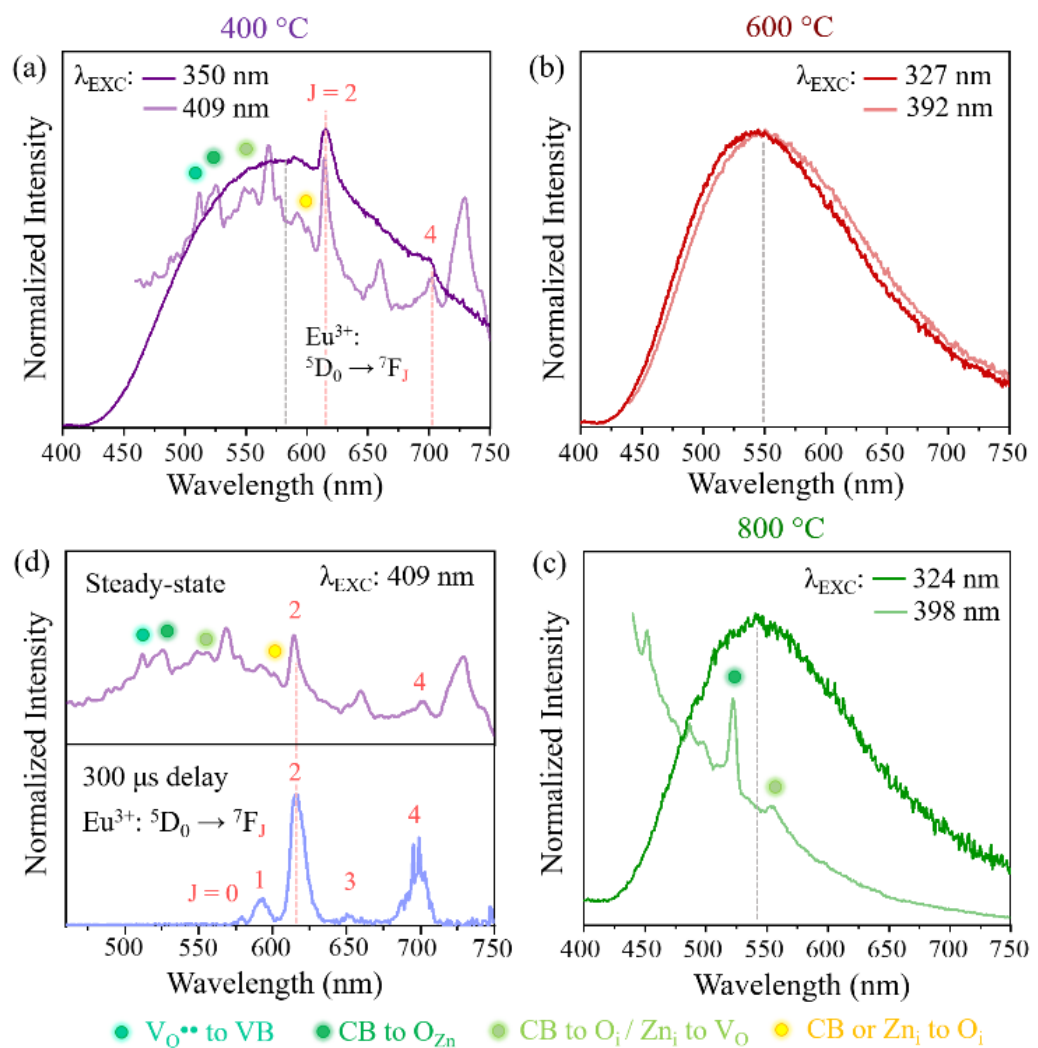

Figure 11. (a-c) Steady-state emission spectra of $\mathrm{ZnO}$ :Eu nanosponges obtained at 400, 600, and $800{ }^{\circ} \mathrm{C}$, respectively, showing different spectral profiles stemming from various $\mathrm{ZnO}$ defect types. (d) Bottom: Time-resolved emission spectrum of the sample obtained at $400{ }^{\circ} \mathrm{C}$, showing $\mathrm{Eu}^{3+}$ emission bands after a delay of $300 \mu$ s. Top: Steady-state spectrum added to highlight the contribution of $\mathrm{ZnO}$ emission on the overall spectral features.

200 and $600^{\circ} \mathrm{C}$ ). Generally speaking, under UV illumination, direct excitation of $\mathrm{Eu}^{3+}$ ions into the ${ }^{5} \mathrm{D}_{\mathrm{J}}$ excited states is possible. Yet, due to the small absorption cross-section of $\mathrm{Eu}^{3+}$ compared to $\mathrm{ZnO}$, this direct excitation pathway can most likely be considered negligible. In addition, the radiative and nonradiative decay of excitons in $\mathrm{ZnO}$ is much faster ( $>10^{2}$ times) when compared to energy transfer rates to $\mathrm{Eu}^{3+}$, which hinders the direct $\mathrm{ZnO}$ (conduction band)-to- $\mathrm{Eu}^{3+}$ energy transfer, but could lead to an emission-reabsorption mechanism. (82) Consequently, defect states in the $\mathrm{ZnO}$ host are key to mediate energy transfer to the higher-laying $\mathrm{Eu}^{3+}$ levels (e.g. ${ }^{5} \mathrm{~L}_{6}$ or ${ }^{5} \mathrm{D}_{3}$ ). Subsequent non-radiative decay to the emitting ${ }^{5} \mathrm{D}_{0}$ level is followed by radiative decay down to the ${ }^{7} \mathrm{~F}_{\mathrm{J}}$ levels giving rise to the characteristic red $\mathrm{Eu}^{3+}$ emission (Figure 10e, left scheme).(83-85)

In contrast to the $400{ }^{\circ} \mathrm{C}$ sample, the samples obtained at 600 and $800^{\circ} \mathrm{C}$ - free from carbonate or other organic residues, but containing Eu-oxide clusters similar to those in the $400{ }^{\circ} \mathrm{C}$ sample and additional $c-\mathrm{Eu}_{2} \mathrm{O}_{3}$ in case of $800{ }^{\circ} \mathrm{C}$ - exhibited only emission bands assigned to the $\mathrm{ZnO}$ matrix, regardless the excitation wavelength used to acquire the emission spectra (Figure 11b,c). In order to ensure that the broad $\mathrm{ZnO}$ emission does not overlap any underlaying $\mathrm{Eu}^{3+}$ emission, additional time- 
resolved emission spectroscopy was performed on the 600 and $800^{\circ} \mathrm{C}$ samples. However, no emission was observed under any of the $\mathrm{ZnO}$ defect- or $\mathrm{Eu}^{3+}$-related excitation wavelengths tested (namely, 330, 409, 392, 398, $464 \mathrm{~nm}$ - data not shown). In our previous study on Eu-doped ZnO nanosponges,(49) similar severe quenching of the Eu emission was observed for samples obtained at temperatures above $400{ }^{\circ} \mathrm{C}$, which was attributed to two possible aspects: (1) the presence of phase separation into $\mathrm{ZnO}$ and $c-\mathrm{Eu}_{2} \mathrm{O}_{3}$ at higher annealing temperatures inducing concentration quenching; and (2) the increased number of oxygen-related defect levels induced by heating in air at elevated temperatures, resulting in less efficient energy transfer from $\mathrm{ZnO}$ defect states to Eu due to the energy mismatch between these oxygen-related energy levels and the Eu excited levels (Figure 10e). Here obtained excitation spectra provide additional insight into the $\mathrm{ZnO}$ defect structure, not available in our previous study (Figure 10b, c). Samples annealed at 600 and $800{ }^{\circ} \mathrm{C}$ exhibited a peak at ca. $395 \mathrm{~nm}$, which can be ascribed to $\mathrm{Zn}_{\mathrm{i}}$ related defects in the $\mathrm{ZnO}$ matrix. The high-laying energy level of this defect type provides a good energy match with the $\mathrm{Eu}^{3+}$ excited states (Figure 10e), potentially enabling ZnO-to-Eu energy transfer. Hence, possible energy transfer from $\mathrm{ZnO}$ to $\mathrm{Eu}$ should not be ruled out, even when higher synthesis temperatures were applied. However, as complete lack of subsequent $\mathrm{Eu}^{3+}$ emission was demonstrated by time-resolved emission spectroscopy, some quenching mechanism must take place. In lanthanidedoped materials, photoluminescence quenching can be caused when the average distance between the luminescent centres is lower than a critical distance, known as concentration or self-quenching. For $\mathrm{Eu}^{3+}$, a critical distance of less than $5 \AA$ is commonly considered as close enough for the exchange interaction mechanism of energy transfer to become operative. $(72,86)$ As demonstrated by EXAFS and DFT studies, the Eu-Eu distances in the formed Eu-oxide clusters $\left(600^{\circ} \mathrm{C}\right)$ are well within this critical range, hence, their contribution to $\mathrm{Eu}^{3+}$ luminescence quenching cannot be ruled out. Moreover, the formation of $c-\mathrm{Eu}_{2} \mathrm{O}_{3}$ particles in the $800{ }^{\circ} \mathrm{C}$ sample is expected to foster non-radiative energy transfer among the luminescent $\mathrm{Eu}^{3+}$ centres. While self-quenching is a plausible explanation for the observed loss of $\mathrm{Eu}^{3+}$ emission, the emission spectrum of the $800^{\circ} \mathrm{C}$ sample can provide additional insight (Figure 11c): the two bands at 522 and $555 \mathrm{~nm}$ can be ascribed to a transition from the $\mathrm{ZnO}$ conduction band to

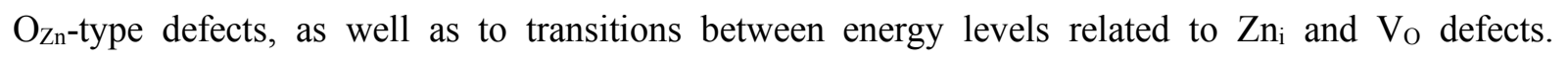
Specifically, the $\mathrm{Zn}_{\mathrm{i}}$ defect states are resonant with the excited $\mathrm{Eu}^{3+}{ }^{5} \mathrm{~L}_{6}$ level, offering a pathway for $\mathrm{ZnO}\left(\mathrm{Zn}_{\mathrm{i}}\right) \rightarrow \mathrm{Eu}^{3+}\left({ }^{5} \mathrm{~L}_{6}\right)$ energy transfer. Yet, as no $\mathrm{Eu}^{3+}$ emission was detected, such energy transfer may compete with the $\mathrm{ZnO}$ matrix-related radiative decay. If the latter is favoured, $\mathrm{ZnO}$-to-Eu energy transfer would be hampered, which ultimately can explain the observation of green $\mathrm{ZnO}$ emission only.

Overall, the observed excitation and emission spectra of $\mathrm{ZnO}: \mathrm{Eu}$ obtained at different temperatures show how the optical properties in $\mathrm{ZnO}: \mathrm{Eu}$ nanosponges are strongly dictated by changes in the local host structure and the dopant ion environment, offering insight into structure-property relationships that are complementary to those found by EXAFS, DFT, XRD, and TEM techniques.

\section{Conclusions}


The mystery of how large amounts of large, alio-valent $\mathrm{Ln}^{3+}$-ions can be introduced into the $\mathrm{ZnO}$ lattice without forming detectable extra phases and virtually no increase in unit cell volume for oxides heated at up to $600-900{ }^{\circ} \mathrm{C}$, has been revealed. In these studies, XRD and TEM showed that for a $\mathrm{ZnO}: 5 \% \mathrm{Eu}$ doping in the nano-crystalline sponges, phase separation into $\mathrm{ZnO}$ with lower amount of Eu doping and $c$ - $\mathrm{Eu}_{2} \mathrm{O}_{3}$ took place from $700{ }^{\circ} \mathrm{C}$. XRD showed only a very small $\mathrm{ZnO}$ unit cell volume expansion of ca. 0.4 vol\% on doping with the larger $\mathrm{Eu}^{3+}$ ions. The $\mathrm{Zn} \mathrm{K}$ edge and $\mathrm{Eu}-\mathrm{L}_{3}$ edge EXAFS provided detailed information on the local bonding conditions which revealed an almost intact $\mathrm{ZnO}$ lattice, in line with the XRD studies, as well as very low Eu to $\mathrm{O}$ coordination numbers close to 5 for the non-phase separated 200 and $600{ }^{\circ} \mathrm{C}$ samples. The experimental data were compared with the formation energy, $\mathrm{Eu}$ coordination number, $\mathrm{Eu}-\mathrm{Eu}$ distances, and $\mathrm{ZnO}$ unit cell volume expansion on $\mathrm{Eu}$ doping, for 23 DFT generated clusters. Very good agreement was obtained with respect to the given properties for 4-8 $\mathrm{Eu}$ atom containing clusters which indicated that these structures closely represent the real structure. This is thus a much unexpected dopant structure with magnetically and optically active molecule-like Eu-oxide clusters, embedded in an almost intact large band-gap semiconductor oxide, with a stability in air up to temperatures of several hundred degrees, depending on doping and $\mathrm{Ln}$ ion. This is exiting as it provides a foundation for combining molecular magnets and semi-conductors, which would make the sensitivity of the latter somewhat relaxed.

\section{ASSOCIATED CONTENT}

\section{Supporting Information}

Details of EXAFS data reduction, Error analysis

\section{AUTHOR INFORMATION}

\section{Corresponding Authors}

*soham.mukherjee@physics.uu.se, soham.chem@gmail.com

* hakan.rensmo@physics.uu.se

* Gunnar.Westin@,kemi.uu.se

\section{Present Addresses}

$£$

I

\section{Notes}

The authors declare no competing financial interest. 
The authors acknowledge STandUP for Energy, the Swedish Research Council (Grant nos. VR 201806465, and 2018-04330), the Swedish Foundation for Strategic Research (Project no. RMA15-0130), the Swedish Energy Agency (Grant no. P43549-1) for financial support. E. H. and E. M. R. gratefully acknowledge the financial support provided by the University of Ottawa, the Canadian Foundation for Innovation (CFI), and the Natural Sciences and Engineering Research Council of Canada (NSERC). MRCAT operations are supported by the Department of Energy and the MRCAT member institutions. This research used resources of the Advanced Photon Source, a U.S. Department of Energy (DOE) Office of Science User Facility operated for the DOE Office of Science by Argonne National Laboratory under Contract No. DE-AC02-06CH11357. Support for author CUS was provided in part by the National Science Foundation under Grant No. DMR-086935.

\section{REFERENCES}

(1) Özgür, Ü.; Alivov, Ya. I.; Liu C.; Teke, A.; Reshchikov, M. A.; Doğan, S.; Avrutin, V.; Cho, S.-J.; Morkoç, H. A comprehensive review of $\mathrm{ZnO}$ materials and devices. J. Appl. Phys. 2005, 98, 041301, 1-103.

(2) Kołodziejczak-Radzimska, A.; Jesionowski, T. Zinc Oxide-From Synthesis to Application: A Review. Materials 2014, 7, 2833-2881.

(3) Wang, Z. L. Zink oxide nanostructures: growth, properties and applications. J. Phys. Condens. Matter. 2004, 16, R829-R858.

(4) Kharisov, B. I.; Kharissova, O. V.; García, B. O.; Méndez, Y. P.; Gómez, de la Fuente I. State of the art of nanoforest structures and their applications. RSC Adv. 2015, 5, 105507-105523.

(5) Cauda, V.; Pugliese, D.; Garino, N.; Sacco, A.; Bianco, S.; Bella, F.; Lamberti, A.; Gerbaldi, C. Multi-functional energy conversion and storage electrodes using flower-like Zinc oxide nanostructures. Energy. 2014, 65, 639-646.

(6) Hosono, E.; Fujihara, S.; Honma, I.; Zhou, H. The fabrication of an upright-standing zinc oxide nanosheet for use in dye-sensitized solar cells. Adv. Mater. 2005, 17, 2091-2094.

(7) Law, M.; Greene, L. E.; Johnson, J. C.; Saykally, R.; Yang, P. Nanowire dye-sensitized solar cells. Nature Mater. 2005, 4, 455-459.

(8) Anta, J. A.; Guillén, E.; Tena-Zaera, R. ZnO-Based Dye-Sensitized Solar Cells. J. Phys. Chem. C 2012, $116(21), 11413-11425$.

(9) Gonzalez-Valls, I.; Lira-Cantu, M. Vertically-aligned nanostructures of ZnO for excitonic solar cells: a review. Energy Environ. Sci. 2009, 2, 19-34.

(10) Selopal, G.S.; Wu, H.-P.; Lu, J.; Chang, Y.-C.; Wang, M.; Vomiero, A.; Concina, I.; Diau, E. W.G. Metal-free organic dyes for $\mathrm{TiO}_{2}$ and $\mathrm{ZnO}$ dye-sensitized solar cells. Sci. Reports 2016, 6, 18756.

(11) Zhang, Y.; Ram, M. K.; Stefanakos, E. K.; Goswami, D. Y. Synthesis, Characterization, and Applications of ZnO Nanowires. J. Nanomater. 2012, 624520, 1-22.

(12) Kumar, S.G.; Kavitha, R., Lanthanide ions doped $\mathrm{ZnO}$ based photocatalysts, Separation, Purification Technol. 2021, 274, 118853, 1-33.

(13) Lee, K. M.; Lai, C. W.; Ngai, K. S.; Juan, J. C. Recent developments of zinc oxide based photocatalyst in water treatment technology: A review. Water Research 2016, 88, 428-448.

(14) Boppella, R.; Anjaneyulu, K.; Basak, P.; Manorama, S. V. Facile Synthesis of Face Oriented ZnO Crystals: Tunable Polar Facets and Shape Induced Enhanced Photocatalytic Performance. J. Phys. Chem. C 2013, 117(9), 4597-4605.

(15) Liu, C.; Yun, F.; Morkoç, H. Ferromagentism of $\mathrm{ZnO}$ and GaN: A review. J. Mater. Sci. Mater Electronics 2005, 16, 555-597.

(16) Pearton, S. J.; Heo, W. H.; Ivill, M.; Norton, D. P.; Steiner T. Dilute Magnetic Semicond. Oxides Semicond. Sci. Technol. 2004, 19, R59-R94. 
(17) Kittilstved, K. R.; Liu, W. K.; Gamelin, D. R. Electronic Structure Origins of Polarity Dependent High- $\mathrm{T}_{\mathrm{C}}$ Ferromagnetism in Oxide Diluted Magnetic Semiconductors. Nature Materials, 2006, 5, 291297.

(18) Willander, M.; Nur, O.; Zhao, Q. X.; Yang, L. L.; Lorenz, M.; Cao, B. Q.; Pérez, J. Z.; Czekalla, C.; Zimmermann, G.; Grundmann, M. Zinc oxide nanorod based photonic devices: recent progress in growth, light emitting diodes and lasers. Nanotechnol. 2009, 20, 332001, 1-40.

(19) Shi, L.; Cui, J.; Zhao, F.; Wang, D.; Xie, T.; Lin Y. High-performance formaldehyde gas-sensors based on three dimensional center-hollow ZnO. Phys. Chem. Chem. Phys. 2015, 17, 31316-31323.

(20) Hoffmann, W. G.; Gad, A. E.; Prades, J. D.; Hernandez-Ramierez, F.; Fiz, R.; Shen, H.; Mathur, S. Solar diode sensor: Sensing mechanism and applications Nano Energy 2013, 2, 514-522.

(21) Choi, K. J.; Jang, H. W. One-Dimensional Oxide Nanostructures as Gas-Sensing Materials: Review and Issues. Sensors 2010, 10, 4083-4099.

(22) Zhang, J.; Wang, S.; Xu, M.; Wan, Y.; Zhu, B.; Zhang, S.; Huang, W.; Wu, S. Hierarchically porous architectures for gas sensor application Cryst. Growth Design 2009, 9, 3532-3537.

(23) Behrens, M.; Robert, Schlögl, R. How to prepare a good $\mathrm{Cu} / \mathrm{ZnO}$ catalyst or the role of solid state chemistry for the synthesis of nanostructured catalysts. Z. Anorg. Allg. Chem. 2013, 639, 2683-2695.

(24) Hosseini-Sarvari, M. Catal. Organic Reactions on ZnO. Current Org. Synth. 2013, 10(5), 697-723.

(25) Martínez-Suárez, L.; Siemer, N.; Frenzel, J.; Marx, D. Reaction Network of Methanol Synthesis over $\mathrm{Cu} / \mathrm{ZnO}$ Nanocatalysts. ACS Catal. 2015, 5(7), 4201-4218.

(26) Polshettiwar, V.; Baruwati, B.; Varma, R. S. Self-assembly of metal oxides into three-dimensional nanostructures: synthesis and application in catalysis. ACS Nano 2009, 3(3), 728-736.

(27) Behrens, M.; Kasatkin, F. S.; Hävecker, S. K. M.; Abild-Pedersen, F.; Zander, S.; Girgsdies, F.; Kurr, P.; Kniep, B.-L.; Tovar, M.; Fischer, R. W.; Nørskov, J. K.; Schlögl, R. The active site of methanol synthesis over $\mathrm{Cu} / \mathrm{ZnO} / \mathrm{Al}_{2} \mathrm{O}_{3}$ industrial catalysts. Science 2012, 336(6083), 893-897.

(28) Caramia, V.; Bozzini, B. Materials science aspects of zinc-air batteries: a review. Mater. Renew. Sustain. Energy 2014, 3, 28, 1-12.

(29) Parker, J. F.; Nelson, E. S.; Wattendorf, M. D; Hevrin, C. N.; Long, J. W.; Rolison, D. R. Retaining the 3D framework of zink sponge anodes upon deep discharge in $\mathrm{Zn}$-air cells. Appl. Mater. Interfaces 2014, 6, 19471-19476.

(30) Garino, N.; Lamberti, A.; Gazia, R.; Chiodoni, A.; Gerbaldi, C. Cycling behavior of sponge-like nanostructured $\mathrm{ZnO}$ as thin film Li-ion battery anodes. J. Alloys Compd. 2014, 15, S454-S458.

(31) Mukherjee, S.; Phuyal, D.; Segre, C. U.; Das, S.; Karis, O.; Edvinsson, T.; Rensmo, H. Structure and Electronic Effects from $\mathrm{Mn}$ and $\mathrm{Nb}$ Co-doping for Low Band Gap BaTiO 3 Ferroelectrics. J. Phys. Chem. C 2021, 125 (27), 14910-14923.

(32) Ganegoda, H.; Mukherjee, S.; Ma, B.; Olive, D. T.; McNeely, J. H.; Kaduk, J. A.; Terry, J.; Rensmo, H.; Segre, C. U. Role of Fe Doping on Local Structure and Electrical and Magnetic Properties of $\mathrm{PbTiO}_{3}$ J. Phys. Chem. C 2021, 125(22), 12342-12354.

(33) Mukherjee, S.; Ganegoda, H.; Kumar, A.; Pal, S.; Segre, C. U.; Sarma, D. D. Evolution of the Local Structure within Chromophoric $\mathrm{Mn}-\mathrm{O}_{5}$ Trigonal Bipyramids in $\mathrm{YMn}_{1-\mathrm{x}} \mathrm{In}_{\mathrm{x}} \mathrm{O}_{3}$ with Composition. Inorg. Chem. 2018, 57 (15), 9012-9019.

(34) Khan, A. H.; Dalui, A.; Mukherjee, S.; Segre, C. U.; Sarma, D. D.; Acharya, S. Efficient SolidState Light-Emitting CuCdS Nanocrystals Synthesized in Air. Angew. Chem. Int. Ed. 201554 (9), 26432648.

(35) Dietl, T.; Ohno, H.; Cibert, J.; Ferrand, D. Zener model description of ferromagnetism in zincblende magnetic semiconductors, Science, 2000, 287, 1019-1022.

(36) Ramachandran, S.; Tiwari, A.; Narayan, $\mathrm{Zn}_{0.9} \mathrm{Co}_{0.1}$-based diluted magnetic semiconducting thin films. J. Appl. Phys. Lett. 2004, 84, 5255-5257.

(37) Yadav, A. K.; Maidul Haque, S.; Shukla, D.; Phase, D. M.; Jha, S. N.; Bhattacharyya, D. Defect mediated reversible ferromagnetism in Co and Mn doped zinc oxide epitaxial films. J. Appl. Phys. 2012, 112, 113917, 1-3.

(38) Mal, S.; Nori, S.; Mula, S.; Narayan, J.; Prater, J.T. Defect mediated reversible ferromagnetism in Co and Mn doped zinc oxide. J. Appl. Phys. 2012, 112, 113917, 1-6.

(39) White, M. A.; Lovejoy, T. C.; Ochsenbein, S. T.; Olmstead, M. A.; Gamelin, D. R. Sputtering Induced $\mathrm{Co}^{0}$ Formation in X-Ray Photoelectron Spectroscopy of Nanocrystalline $\mathrm{Zn}_{1-x} \mathrm{Co}_{x} \mathrm{O}$ Spinodal Enrichment Models. J. Appl. Phys., 2010, 107, 103917. 
(40) Park, C. I.; Jin, Z.; Jeong, E.-S.; Hwang, I. H.; Han, S.W. Local structural properties of Co-ionimplanted $\mathrm{ZnO}$ nanorods J. Korean Phys. Soc. 2013, 63, 2165-2169.

(41) Sanyal, B.; Grånäs, O.; Knut, R.; Coleman, V. A.; Thunström, P.; Iuşan, D. M.; Karis, O.; Eriksson, O.; Westin. G. Electronic structure of Co doped ZnO: Theory and experiment. J. Appl. Phys. 2008, 103, 07D130, 1-3.

(42) Iuşan, D.; Knut, R.; Sanyal, B.; Karis, O.; Eriksson, O.; Coleman, V. A.; Westin, G.; Wikberg, J. M.; Svedlindh, P. Electronic structure and chemical and magnetic interactions in $\mathrm{ZnO}$ doped with Co and Al: Experiments and ab initio density-functional calculations. Phys. Rev. 2008, B 78, 085319, 1-9. (43) Knut, R.; Wikberg, J. M.; Lashgari, K.; Coleman, V. A.; Westin, G.; Svedlindh, P.; Karis, O. Magnetic and electronic characterization of highly Co-doped $\mathrm{ZnO}$ : An annealing study at the solubility limit. Phys. Rev. B 2010, 82, 094438, 1-7.

(44) Kronawitter, C. X.; Zegkinoglou, I.; Shen, S.-H., Liao, P.; Cho, I. S.; Zandi, O.; Liu, Y.-S.; Lashgari, K.; Westin, G.; Guo, J.-H.; Himpsel, F. J.; Carter, E. A.; Zheng, X. L.; Hamann, T. W.; Koel, B. E.; Mao, S. S.; Vayssieres, L. Titanium incorporation into hematite photoelectrodes: theoretical considerations and experimental observations. Energy Environ. Sci., 2014, 7, 3100-3121.

(45) Marin, R.; Jaque, D. Doping lanthanide ions in colloidal semiconductor nanocrystals for brighter luminescence. Chem. Rev. 2021, 121, 1425-1462.

(46) Kumar, V.; Ntwaebrowa, O. M.; Soga, T.; Dutta, V.; Swart, H.C. rare earth doped zinc oxide nanophosphor powder: A future material for solid state lighting and solar cells. Photonics. 2017, 4, 2613-2637.

(47) Girish Kumar, S.; Kavitha, R. Lanthanide ions doped ZnO based photocatalysts. Separation, Purif. Technol. 2021, 274, 118853, 1-33.

(48) Katea, S. N.; Broqvist, P.; Kullgren, J.; Hemmer, E.; Westin, G. Fast, Low-Cost Synthesis of ZnO:Eu Nanosponges and the Nature of Ln Doping in ZnO. Inorg. Chem. 2020, 59, 7584-7602.

(49) Marin, R.; Oussta, F.; Naim Katea, S. Prabhudev, S.; Botton, G. A.; Westin, G.; Hemmer E. Europium-doped $\mathrm{ZnO}$ Nanosponges - Controlling Optical Properties and Photocatalytic Activity. J. Mater. Chem. C. 2019, 7, 3909-3919.

(50) Perdew, J. P.; Burke, K.; Ernzerhof, M. Generalized gradient approximation made simple. Phys. Rev. Lett. 1996, 77, 3865-3868.

(51) Perdew, J. P.; Burke, K.; Ernzerhof, M. Generalized gradient approximation made simple. Phys. Rev. Lett. 1996, 78, 1396.

(52) Kresse, G.; Hafner, J. Ab initio molecular dynamics for liquid metals. Phys. Rev. B 1993, 47, 558561.

(53) Kresse, G.; Hafner, J. Ab initio molecular-dynamics simulation of the liquid-metal-amorphoussemiconductor transition in germanium. Phys. Rev. B, 1994, 49, 14251-14269.

(54) Kresse, G.; Furthmüller, J. Efficiency of ab-initio total energy calculations for metals and semiconductors using a plane-wave basis set. Comput. Mater. Sci. 1996, 6(1), 15-50.

(55) Kresse, G.; Furthmüller, J. Efficient iterative schemes for ab initio total-energy calculations using a plane-wave basis set. Phys. Rev. B 1996, 54, 11169-11186.

(56) Blöchl, P. E. Projector augmented-wave method. Phys. Rev. B 1994, 50, 7953-17979.

(57) Kresse, G.; Joubert, D. From ultrasoft pseudopotentials to the projector augmented-wave method. Phys. Rev. B 1999, 59, 1758-1775.

(58) Katea, S. N.; Hajduk, Š.; Crnjak Orel, Z.; Westin, G. Low Cost, Fast Solution Synthesis of 3D Framework ZnO Nanosponges. Inorg. Chem. 2017, 56, 15150-15158.

(59) Shannon, R.D. Revised effective ionic radii and systematic studies of interatomic distances in halides and chalcogenides. Acta Cryst. 1976, A32, 751-767.

(60) Zhang, Y.; Liu, Y.; Wu, L.; Xie, E.; Chen, J. Photoluminescence and $\mathrm{ZnO} \rightarrow \mathrm{Eu}^{3+}$ energy transfer in $\mathrm{Eu}^{3+}$-doped $\mathrm{ZnO}$ nanospheres. J. Phys. D: Appl. Phys. 2009, 42, 085106.

(61) Samah M. AhmedPaul Szymanski, Lotfia M. El-Nadi, Mostafa A. El-Sayed, Energy-Transfer Efficiency in Eu-Doped ZnO Thin Films: The Effects of Oxidative Annealing on the Dynamics and the Intermediate Defect States, ACS Applied Materials \& Interfaces 2014, 6, 3, 1765-1772.

(62) Yang, Y. H.; Feng, Y.; Zhu, H. G.; Yang, G. W. Growth, structure, and cathode luminescence of Eu-doped $\mathrm{ZnO}$ nanowires prepared by high-temperature and high-pressure pulsed-laser deposition. $J$. Appl. Phys. 2010, 107, 053502. 
(63) Zhong W.-W.; Guan, G.-W.; Liu, X.-L..; Zhang, Li.; Liu, Y.-P.; Li, Z.-G.; Chen, W.-P. J. Effect of annealing on the structure and photoluminescence of Eu-doped $\mathrm{ZnO}$ nanorod ordered array thin films Nanomater. 2012, 263679, 1-6.

(64) Sebastian Geburt, Michael Lorke, Andreia L. da Rosa, Thomas Frauenheim, Robert Röder, Tobias Voss, Uwe Kaiser, Wolfram Heimbrodt, and Carsten Ronning, Intense Intrashell Luminescence of EuDoped Single $\mathrm{ZnO}$ Nanowires at Room Temperature by Implantation Created Eu-Oi Complexes. Nano Lett. 2014, 14, 4523-4528

(65) Assadi, M. H. N.; Zhang, Y.; Zheng, R.-K.; Ringer, S. P.; Li, S. Structural and electronic properties of Eu- and Pd-doped ZnO. Nanoscale Research Lett. 2011, 6:357

(66) El Hachimi, A.G.; Ould NE, M.L.; El Yousfi, A.; Benyoussef, A.; El Kenz, A. Enhancing optical absorption in visible light of $\mathrm{ZnO}$ co-doped with europium and promethium by first-principles study through modified Becke and Johnson potential scheme, J. Rare Earths, 2019, 37, 416-421.

(67) Lorke, M.; Frauenheim, T.; da Rosa, A. L. Many-body electronic structure calculations of Eu-doped ZnO. Phys. Rev. 2016, B 93, 115132.

(68) Zhang, X.J.; Mi, W.B.; Wang, X.C.; Bai, H.L. First-principles prediction of electronic structure and magnetic ordering of rare-earth metals doped ZnO. J. Alloys Compd. 2014, 617, 828-833.

(69) Yumak, A.; Yahsi, U.; Petkova, P.; Boubake, K. Europium doping-induced stability and quantum confinement effect in $\mathrm{ZnO}$ quantum well wires QWW: Electronic structure calculation and material structural investigation in terms of band-gap shift. Materials Letters 2016, 164, 89-92.

(70) Yu, Q.; Ai, T.; Jiang, L.; Zhang, Y.; Li, C.; Yuan, X. Efficient energy transfer in Eu-doped ZnO on diamond film. RSC Adv. 2014, 4, 5394653949.

(71) Westin, G.; Moustiakimov, M.; Kritikos, M. Synthesis, Characterization, and Properties of Three Europium 2-Propoxides: $\left[\mathrm{Eu}_{4}\left(\mathrm{OPr}^{\mathrm{i}}\right)_{10}\left(\mathrm{HOPr}^{\mathrm{i}}\right)_{3}\right] 2 \mathrm{HOPr}^{\mathrm{i}}, \mathrm{Eu}_{5} \mathrm{O}\left(\mathrm{OPr}^{\mathrm{i}}\right)_{13}$, and $\mathrm{EuAl}_{3}\left(\mathrm{OPr}^{\mathrm{i}}\right)_{12}$. Inorg. Chem. 2002, 41, 3249-3258.

(72) Binnemans, K. interpretation of europium (III) spectra. Coord. Chem. Rev. 2015, 295, 1-45.

(73) Chen, D.; Wang, Z.; Ren, T.; Ding, H.; Yao, W.; Zong, R.; Zhu, Y. Influence of Defects on the Photocatalytic Activity of ZnO. J. Phys. Chem. C 2014, 118, 15300-15307.

(74) Ran. W.; Noh, H. M.; Park, S. H.; Moon, B. K.; Jeong, J. H.; Kim, J. H., Shi, J. Scientific Reports, 2018, 8, 5936.

(75) Yang, L.; She, Y.; Zhao, S.; Yue, S.; Wang, Q.; Hu, A.; Zhang, W. Synthesis and optical properties modulation of $\mathrm{ZnO} / \mathrm{Eu}_{2} \mathrm{O}_{3}$ nanocable arrays. J. Appl. Phys. 2010, 108, 104301.

(76) Wakefield, G.; Keron, H. A.; Dobson, P. J.; Hutchison, J. H. Synthesis and Properties of Sub-50nm Europium Oxide Nanoparticles. J. Colloid Interface Sci. 1999, 215, 179-182

(77) Roof, I. P.; Smith, M. D.; Park, S.; zur Loye, H.-C. EuKNaTaO 5 : Crystal Growth, Structure and Photoluminescence Property J. Am. Chem. Soc. 2009, 131, 4202-4203.

(78) Zheng, Y.; Chen, C.; Zhan, Y.; Lin, X.; Zheng, Q.; Wei, K.; Zhu, J.; Zhu, Y. Luminescence and Photocatalytic Activity of $\mathrm{ZnO}$ Nanocrystals: Correlation between Structure and Property. Inorg.

Chem. 2007, 46, 6675-6682

(79) Can, M. M.; Shah, S. I.; Doty, M. F.; Haughn, C. R.; Firat, T. Electrical and optical properties of point defects in ZnO thin films. J. Phys. D: Appl. Phys. 2012, 45, 195104.

(80) Raji, R.; Gopchandran, K. G. ZnO nanostructures with tunable visible luminescence: Effects of kinetics of chemical reduction and annealing. J. Sci.: Adv. Mater. Dev. 2017, 2, 51-58.

(81) Jang, K. W.; Meltzer, R. S. Homogeneous and inhomogeneous linewidths of $\mathrm{Eu}^{3+}$ in disordered crystalline systems Phys. Rev. B 1995, 52, 6431-6439.

(82) Du, Y.-P.; Zhang, Y.-W.; Sun, L.-D.; Yan, C.-H. Efficient Energy Transfer in Monodisperse EuDoped ZnO Nanocrystals Synthesized from Metal Acetylacetonates in High-Boiling Solvents. J. Phys. Chem. C 2008, 112, 12234-12241.

(83) Ghosh, S.; Kumar K., U. M.; Bhaktha, B. N. S. Heat-treatment controlled structural and optical properties of sol-gel fabricated $\mathrm{Eu}$ : ZnO thin films. Opt. Mater. 2017, 64, 288-294.

(84) Senapati, S.; Nanda, K. K. Red emitting Eu:ZnO nanorods for highly sensitive fluorescence intensity ratio based optical thermometry. J. Mater. Chem. C 2017, 5, 1074-1082. 
(85) Ahmed, S. M.; Szymanski, P.; El-Nadi, L- M.; El-Sayed, M- A. Energy-Transfer Efficiency in Eu-Doped ZnO Thin Films: The Effects of Oxidative Annealing on the Dynamics and the Intermediate Defect States. ACS Appl. Mater. Interfaces 2014, 6, 1765-1772.

(86) Mangalam, V.; Pita, K. Effect of the interaction distance on $614 \mathrm{~nm}$ red emission from $\mathrm{Eu}^{3+}$ ions due to the energy transfer from $\mathrm{ZnO}-\mathrm{nc}$ to $\mathrm{Eu}^{3+}$ ions Opt. Mater. Expr. 2018, 8 (10) 3115-3132. 